Please do not remove this page

RMIT

UNIVERSITY

\title{
Optimum solids concentration in an agitated vessel
}

Wang, Steven; Parthasarathy, Rajarathinam; Wu, Jie; Slatter, Paul

https://researchrepository.rmit.edu.au/esploro/outputs/9921859340001341/filesAndLinks?institution=61RMIT_INST\&index=null

Wang, S., Parthasarathy, R., Wu, J., \& Slatter, P. (2014). Optimum solids concentration in an agitated vessel. Industrial and Engineering Chemistriy Research, 53(10), 3959-3973. https://doi.org/10.1021/ie402252c

Document Version: Accepted Manuscript

Published Version: https://doi.org/10.1021/ie402252c

Repository homepage: https://researchrepository.rmit.edu.au

(c) 2014 American Chemical Society

Downloaded On 2023/04/26 19:37:31 +1000

Please do not remove this page 
Thank you for downloading this document from the RMIT Research Repository.

The RMIT Research Repository is an open access database showcasing the research outputs of RMIT University researchers.

RMIT Research Repository:http://researchbank.rmit.edu.au/

\section{Citation:}

Wang, S, Parthasarathy, R, Wu, J and Slatter, P 2014, 'Optimum solids concentration in an agitated vessel', Industrial \& Engineering Chemistriy Research, vol. 53, no. 10, pp. 3959-3973

See this record in the RMIT Research Repository at:

https://researchbank.rmit.edu.au/view/rmit:24515

Version: Accepted Manuscript

Copyright Statement: ‘ 2014 American Chemical Society

Link to Published Version:

http://pubs.acs.org/doi/abs/10.1021/ie402252c 


\title{
Optimum Solids Concentration in an Agitated Vessel
}

\author{
Steven Wang \\ Division of Earth Science and Resource Engineering, Commonwealth Scientific and \\ Industrial Research Organization, Clayton, 3169, Australia \\ Rajarathinam Parthasarathy, Paul Slatter \\ Rheology and Materials Processing Centre, School of Civil, Environmental and \\ Chemical Engineering, RMIT University, Melbourne, 3001, Australia \\ Jie Wu \\ Division of Process Science and Engineering, Commonwealth Scientific and Industrial \\ Research Organisation, Highett, 3190, Australia
}

\begin{abstract}
Particle suspension in high concentration slurries has been studied using radial-, mixed- and axial-flow impellers. Impeller power measurements in this study are linked to the mass of solids suspended in the agitation system rather than suspension volume. It is based on the consideration that the rate of dissolution or reaction depends to a large extent on the exposed surface area or mass of solids and may not be affected by the suspension volume, once off-bottom suspension is achieved. It is found that specific power, based on the mass of solids can be minimized by operating the system at relatively higher solids concentrations in the range of $0.20-0.35(\mathrm{v} / \mathrm{v})$ for the solids, impeller types and geometrical conditions used in this work. Overall, improved energy efficiency can be achieved by using higher power number impellers under unbaffled conditions over a range of solids concentrations. A case example is illustrated to demonstrate the benefits of adopting some of the optimization methods highlighted in this paper.
\end{abstract}


Keywords: optimum solids concentration, specific power, mass of solids, high solids concentration 


\section{Introduction}

Mechanically agitated vessels are widely used in industry for solid-liquid mixing in processing plants including for operations such as dispersion of solids, dissolution, crystallization, precipitation, adsorption, desorption, ion exchange, leaching, digestion, solid-catalyzed reaction and suspension polymerization. Process intensification in these vessels often requires that the production yield per unit volume per unit time be increased without the need for major changes in the plant. Process intensification can be achieved by increasing the throughput or yield through improved physical processes such as efficient mixing since it is entirely impractical to reduce the size or volume of existing agitated tanks. In such instances, it is beneficial to maintain the vessel volume and intensify the process by increasing the solids throughput whilst minimising energy consumption. When solids throughput is increased, it leads to an increase in the impeller speed required to suspend the solids off the tank bottom which consequently increases the energy input to the system. Therefore, it is essential to determine suitable mixing vessel and impeller configurations which can achieve the ‘just suspended condition' for high concentration slurries with minimum energy input.

One of the important operating parameters that determine the efficiency of solid-liquid mixing vessels is the critical impeller speed at which the just suspended condition occurs, which is denoted as $\mathrm{N}_{\mathrm{js}}$. Energy input at $\mathrm{N}_{\mathrm{js}}$ is regarded as a critical design factor for solid-liquid mixing vessels and it is a function of the process operating condition like solids concentration, and geometric parameters like impeller and baffle types. Studies associated with solids suspensions in agitated vessels have been well documented over the past 40 years. Nienow (1968), Chapman (1983a, b) and Nienow (1985) investigated the effect of impeller diameter on $\mathrm{N}_{\mathrm{js}}$ and concluded that $\mathrm{N}_{\mathrm{js}}$ 
decreases with the increasing impeller diameter for a given tank diameter. Zwietering (1958), Nienow (1968) and Raghava Rao et al. (1988) evaluated the relationship between the impeller off-bottom clearance and $\mathrm{N}_{\mathrm{js}}$ and found that reduction in $\mathrm{N}_{\mathrm{js}}$ can be achieved by decreasing the off-bottom impeller clearance.

Reporting the impeller speed, rather than the power draw at complete suspension has two drawbacks: 1) it is not possible to compare the energy efficiency or power consumption of a given system with other work, and 2) the estimates of the impeller power draw using $\mathrm{N}_{\mathrm{js}}$ can be inaccurate by up to $20 \%$ because the power number at the complete suspension condition can be a function of solids concentration (Drewer et al., 1994; Bubbico et al., 1998). Therefore it is highly desirable to compare the efficiency of mixing systems in terms of the system's specific power input. Such a comparison can enable energy consumption reductions in inefficient processing plants such as mineral processing plants where a series of large and extremely energy intensive solids suspension tanks are often used.

Researchers have focused on determining various ways to minimize energy consumption in slurry handling tanks. One of them is to implement different tank geometries. Kasat et al. (2005) concluded that the choice of a proper impeller for solid suspension is the key in achieving economic success in the process. Wu et al. (2010a) found that the removal of baffles can play an effective role in drastically reducing the power draw for suspending the particles off the tank bottom. They found that about a $70 \%$ energy saving can be achieved under high solids loading $(>0.40)$ under unbaffled conditions. They also demonstrated that under unbaffled conditions, axial impellers are more energy intensive than radial impellers which is contradictory to conventional 
findings (Zwietering 1958). In spite of these studies, there is a lack of understanding on impeller power consumption for solids suspension in agitated vessels especially for those handling high concentration slurries $(>0.20 \mathrm{v} / \mathrm{v})$. Most of the previous studies have used a limited range of solid concentrations (0.01-0.20 v/v) (Wu et al., 2002).

Most of the previous work considered the impeller power input on the basis of the volume of the vessel or reactor (Drewer et al., 1994; Wu et al., 2002). However, Drewer et al. (2000) suggested that, except for processes such crystallisation which requires suspension homogeneity, the rate of mass transfer or reaction is independent of agitation and the vessel volume once the suspension of solids is achieved. They suggested that for such processes the reaction rate is controlled by solid surface area and therefore, the volume of reactor does not play a critical role. Based on that consideration, they have used the specific power input expressed on the basis of total mass of solids suspended to evaluate their experimental data. They reported that when the specific power determined as impeller power at the just suspended condition $\left(\mathrm{P}_{\mathrm{js}}\right)$ per unit mass of suspended solids $\left(\mathrm{M}_{\mathrm{s}}\right)$ is plotted against solid concentration, it has a minimum value of around $30 \%$ solids v/v. This finding was reported for all the impeller types used by the authors. This result is somewhat consistent with the results reported by Ragav Rao et al. (1998) who found that $\left(\mathrm{P}_{\mathrm{js}} / \mathrm{M}_{\mathrm{s}}\right)$ has a decreasing trend with increases in solids concentration. They found that less power input is required to suspend $6.6 \mathrm{wt} \%$ solids as compared to that for $0.34 \mathrm{wt} \%$ solids.

Expressing the impeller power draw at $\mathrm{N}_{\mathrm{js}}$ on the basis of total solids mass as was done by Drewer et al. (2000) is logical considering that in many processes such as leaching and digestion, the rate of reaction is largely influenced by the solid specific surface area. 
Therefore, it is appropriate to use a specific power expressed on the basis of mass of suspended solids to determine the optimum solid concentration to be used in solidliquid reactors. Since the attempt of Drewer et al., this approach to determine the optimum solid concentration has not been used in many studies and therefore warrants further investigation. Furthermore Drewer et al.'s work focused mainly on solids suspension in baffled tanks. Considering that removing baffles lead to reductions in the impeller power draw for solids suspensions as shown by Wu et al. (2010a, b), it will be interesting to investigate the relationship between specific power in terms of mass of solids and solids concentrations in unbaffled tanks. In addition, it will be useful to investigate the effects of variables such as particle size, impeller type and number of impellers on specific power input based on total solid mass.

Zwietering et al. (1958) introduced the visual observation method to determine $\mathrm{N}_{\mathrm{js}}$ in which he defined it as the impeller speed at which no solid particles are observed to remain at rest on the tank bottom for more than 1 or 2 seconds. This criterion is frequently used to measure $\mathrm{N}_{\mathrm{js}}$ by many researchers (Bujalski et al., 1999; Drewer et al., 2000). However, Kasat and Pandit (2005) pointed out that excessive energy is required to lift small amounts of solids from relatively stagnant regions around the periphery of the vessel bottom, especially near the baffles or at the centre of the vessel bottom because the liquid circulation is not strong enough there as compared to that in the bulk of the vessel. They also noted that from a practical point of view these fillets are generally insignificant but they could lead to a 20 - 50\% increase in the impeller speed required for off-bottom suspension of solids. Wu et al. (2010a) also pointed out that this definition is problematic in practice because a small quantity of stationary particles in a corner may not be suspended even at a very high stirring speed, and that it is difficult to rely on the status of a small quantity of particles to determine the just-suspended 
condition. In addition to this, Zwietering's method is significantly influenced by subjective evaluation. Its repeatability is poor due to the complicated flow pattern in a solid-liquid system particularly under a high solids loading condition (0.20-0.50 (v/v)).

In general, it should be noted that for processes involving chemical reactions, the kinetics could be either diffusion-limited or non diffusion-limited. For non diffusionlimited processes, it is often sufficient to keep the solids just suspended off the tank bottom. Additional power input, which tends to increase suspension homogeneity, does not lead to increased reaction rates, and so is wasteful. Thus, it is sufficient to consider the specific power input into the system at the just off-bottom solids suspension condition. This is the basis on which all the power measurements and analyses were carried out in this paper.

This paper describes a study which investigates the impact of solid loading on $\left(\mathrm{P}_{\mathrm{js}} / \mathrm{M}_{\mathrm{s}}\right)$ in a $0.39 \mathrm{~m}$ agitated vessel. The results are applicable to the overall goal of developing optimized industrial agitator designed to minimize the power consumption for suspending a unit mass of solid particles in tanks, where the off-bottom solids suspension is a limiting factor.

\section{Experimental}

\section{Experimental equipment and method}

All experiments were carried out in a cylindrical, flat-bottomed perspex tank, with diameter $\mathrm{T}=0.39 \mathrm{~m}$, placed inside a rectangular outer glass tank (Figure 1 ). The cylindrical tank was equipped with four equally spaced baffles, each protruding a distance $B=0.0325 \mathrm{~m}$ into the tank, giving a width to tank diameter ratio $(\mathrm{B} / \mathrm{T})$ of 1/12. The space between the inner and outer tanks was filled with tap water which helped to 
minimize the optical distortion caused by the curvature of the inner tank during flow visualisation. The off-bottom impeller clearance was set at T/3. Impellers were mounted on a centrally driven shaft attached to an Ono Sokki torque transducer and a speed detector. The impeller shaft was driven by an electric motor having a maximum speed of 500 revolutions per minute (RPM). The shaft speed was varied using a variable frequency drive.

Tap water was used as the liquid phase in all the experiments. The liquid height in the inner tank $(\mathrm{H})$ was maintained equal to the tank diameter. Spherical glass ballotini particles with a density of $2500 \mathrm{~kg} / \mathrm{m}^{3}$ were used as the solid particles. Three different glass particles (See Table 1) with mean particle sizes $\left(\mathrm{d}_{50}\right)$ of 90, 165 and $320 \mu \mathrm{m}$ were used in this work.

Impellers used in this work are shown in Figure 2 and they were: 6-bladed Rushton turbine (DT6) with the impeller diameter to tank diameter ratio (D/T) of 0.4, two A310 impellers with $\mathrm{D} / \mathrm{T}$ ratios of 0.4 and 0.5 , and two $45^{\circ}$ pitched blade turbine impellers (45PBT4) both with $(\mathrm{D} / \mathrm{T})$ ratio of 0.4 but one with thicker blades $(2 \mathrm{~mm}, \mathrm{t} / \mathrm{W}=0.125)$ and the other with thinner blades $(1 \mathrm{~mm}, \mathrm{t} / \mathrm{W}=0.062)$. One mixed-flow impeller with 6 blades (30PBT6) was also used in this study. The other dimensions and details of the impellers are shown in Table 2. The impeller clearance from the tank bottom was set at 1/3 $\mathrm{T}$, where $\mathrm{T}$ is the tank diameter. For dual impeller system, impeller spacing was set equal to one impeller diameter i.e., $160 \mathrm{~mm}$. 


\section{Determination of the critical impeller speed for the 'just suspended' condition $\mathbf{N}_{\mathrm{js}}$}

In this work, a method proposed by Hicks et al. (1997) was used to determine $\mathrm{N}_{\mathrm{js}}$. In this method, bed height of the solids settled at the tank bottom was used as a means of determining $\mathrm{N}_{\mathrm{js}}$. To determine $\mathrm{N}_{\mathrm{js}}$ according to this method, the impeller speed was initially increased to a sufficiently high value so that no particles remain stationary at the tank bottom. At this condition, as shown in Figure 3a, all particles are moving freely within the liquid and the suspension concentration will be nearly uniform $\left(\mathrm{H}_{\mathrm{S}} \sim \mathrm{H}\right)$. The impeller speed is then decreased gradually until a thin layer of solid bed appears at the tank bottom (Figure 3b). The impeller speed is then increased slightly until the settled solid bed disappears. The speed at which the solid bed disappears is designated as $\mathrm{N}_{\mathrm{js}}$. If the impeller speed is decreased below $\mathrm{N}_{\mathrm{js}}$, a visible solid bed appears whose height is designated as $\mathrm{H}_{\mathrm{B}}$ (Figure 3c and 3d). In this study, the height of the settled solid bed $\left(\mathrm{H}_{\mathrm{B}}\right)$ was measured between two consecutive baffles. The ratio of settled bed height $\left(\mathrm{H}_{\mathrm{B}}\right)$ and total liquid height $(\mathrm{H})$ is plotted against the impeller speed in Figure 4 for 30PBT6 to suspend solids at different concentrations. It can be seen that the normalised solid bed height is zero at $\mathrm{N}_{\mathrm{js}}$ and it increases with decreasing in impeller speed. This method of using the settled solid bed height for determining $\mathrm{N}_{\mathrm{js}}$ has been demonstrated to be quite reliable for suspensions with high solids concentrations (Wu et al., 2010a,b)

\section{Impeller power draw measurement}

The absolute torque $\mathrm{T}_{a}$ experienced by the impeller shaft was measured using the torque transducer and determined according to the following equation:

$T_{a}=T_{m}-T_{r}$ 
where $T_{m}$ is the torque measured during the experiments and $T_{r}$ represents the residual torque due to mechanical friction in the bearing which is determined by operating the impeller without the liquid and solid in the tank. The power consumption in the agitation system can be now determined as:

$P=2 \pi N T_{a}=2 \pi N\left(T_{m}-T_{r}\right)$

where is $P$ is the impeller power draw (W) and $\mathrm{N}$ is the impeller rotational speed in revolutions per second (rps). The specific power input, $\varepsilon_{j s}(\mathrm{~W} / \mathrm{kg})$, is defined as the impeller power draw, $P(\mathrm{~W})$, divided by the total solid mass in suspension, $M_{s}(\mathrm{~kg})$, where

$\varepsilon_{j s}=\frac{P_{j s}}{M_{s}}=\frac{2 \pi N_{j s}\left(T_{m}-T_{r}\right)}{M_{s}}$.

It can be seen that the smaller the $\varepsilon_{j s}$ value, the less energy is required to suspend the solids in the vessel.

\section{Results}

Results are presented here to describe the effects of solids concentration, impeller type, baffle, impeller dimensions, the number of impellers and particle size on the specific power input required to just suspend the particles. This leads to a discussion of the optimum solids concentration and the introduction of a simple model relating the power consumption to the solids concentration. An optimum agitator design will be proposed based on the key findings from this study. 


\section{Effect of solids concentration}

Impeller power per unit slurry volume $\left(\mathrm{P}_{\mathrm{js}} / \mathrm{V}\right)$ values required to just suspend the particles off the tank bottom are shown in Figure 5 as a function of solids concentration. The impellers used were a down-pumping $30^{\circ}$ pitched-bladed turbine (30PBT6) and a hydrofoil impeller (A310). As is expected, the specific power input $\left(\mathrm{P}_{\mathrm{js}} / \mathrm{V}\right)$ values for both A310 and 30PBT6 increase with increasing solids concentration in both baffled and unbaffled configurations. In each case, under baffled conditions, $\mathrm{P}_{\mathrm{js}} / \mathrm{V}$ increases gradually with an increase in solids concentration up to $0.30 \mathrm{v} / \mathrm{v}$ and thereafter increases rapidly as the concentration approaches the maximum achievable concentration of $\left(\mathrm{C}_{\mathrm{v}}\right)_{\max }=0.52 \mathrm{v} / \mathrm{v}$ for this configuration (Reference here would be useful). Under baffled conditions, regardless of the impeller type, the ratio of maximum solids loading $\left(\left(\mathrm{C}_{\mathrm{v}}\right)_{\max }\right)$ to solids packing coefficient $\left(\mathrm{C}_{\mathrm{b}}\right)$ may be expressed as: $\left(C_{v}\right)_{\max } / C_{b} \approx 0.90$, where the value of the packs coefficient $\left(\mathrm{C}_{\mathrm{b}}\right)$ was found to be 0.58 for the particles used in this study (Reference here would be useful for the packing coefficient). Under unbaffled conditions, the maximum achievable solids concentration $\left(\mathrm{C}_{\mathrm{v}}\right)_{\max }$ is $0.56 \mathrm{v} / \mathrm{v}$ which is higher than that under baffled conditions (Wang et al. ,2012). Based on Figure 5, for the unbaffled tank $\left(C_{v}\right)_{\max } / C_{b} \approx 0.98$.

As shown in Figure 5, for all $\mathrm{C}_{\mathrm{v}}$ values, $\mathrm{P}_{\mathrm{js}} / \mathrm{V}$ values under unbaffled conditions are lower than those under baffled conditions. These results show clearly that the removal of baffles is highly beneficial in decreasing the impeller power input, especially when very high solid concentrations are used. Among the many possible reasons for the increased $P_{j s} / V$ at high $C_{v}$, increased slurry viscosity could be the main one. Slurry viscosity values predicted using different correlations, reported by Honek et al. (2005), are shown in Figure 6 for a range of $\mathrm{C}_{\mathrm{v}}$ values (Could you please use distinctive colors 
for the curves especially for the blue curves?). These correlations are based on $\mathrm{C}_{\mathrm{b}}$ and $\mathrm{C}_{\mathrm{v}}$. The influence of solids loading on slurry viscosity is not significant in the range $0.15<\mathrm{C}_{\mathrm{v}}<0.45 \mathrm{v} / \mathrm{v}$. However, as $\mathrm{C}_{\mathrm{v}}$ increases beyond $0.45 \mathrm{v} / \mathrm{v}$, the effective viscosity increases steeply. This increase could possibly cause a sudden change in the fluid flow pattern, most likely from turbulent to transitional or even to laminar flow. At such high solids concentrations, turbulence is most likely to be suppressed due to the solids packing effect. Therefore, it is not surprising to see a sharp rise in impeller specific power draw at ultra-high solid concentrations.

As mentioned above, another measure by which the power input at $\mathrm{N}_{\mathrm{js}}$ can be expressed is on the basis of mass of solids suspended. The power input per unit mass of solids $\varepsilon_{\mathrm{js}}$ is defined in Equation (3). Experimental data of $\varepsilon_{\mathrm{js}}$ at $\mathrm{N}_{\mathrm{js}}$ are shown in Figure $7 \mathrm{a}$ as a function of $\mathrm{C}_{\mathrm{v}}$ for 30PBT6 under baffled conditions. It is interesting to note that contrary to expectations, the $\varepsilon_{\text {js }}$ value does not increase with increasing $C_{v}$. Instead, $\varepsilon_{\text {js }}$ decreases with increasing $C_{v}$ until a critical value is reached and thereafter it begins to increase again. This trend was observed with $\varepsilon_{\mathrm{js}}$ values for other impellers too (Wang et al. , 2012).

The $\mathrm{C}_{\mathrm{v}}$ value at which $\varepsilon_{\mathrm{js}}$ is a minimum could be designated as the 'optimum solids concentration $\left(\mathrm{C}_{\mathrm{v}}\right)_{\text {osc }}$ ' because it represents a condition at which the energy input into the system through impeller rotation is applied most efficiently. The $\left(\mathrm{C}_{\mathrm{v}}\right)_{\text {osc }}$ for 30PBT6 is $0.25 \mathrm{v} / \mathrm{v}$ as can be seen in Figure $7 \mathrm{a}$. It is interesting to note that $\varepsilon_{\mathrm{js}}$ at $0.06 \mathrm{v} / \mathrm{v}$ is 3 times greater than that at $\left(\mathrm{C}_{\mathrm{v}}\right)_{\text {osc }}=0.25 \mathrm{v} / \mathrm{v}$. Similar trends were observed for other impellers under unbaffled conditions too. These results suggest that operating the 
process around $\left(\mathrm{C}_{\mathrm{v}}\right)_{\text {osc }}$ is better than operating at lower $\mathrm{C}_{\mathrm{v}}$ values because slurries with higher solids concentrations can be suspended with a lower specific power input.

The increased impeller energy efficiency that can be obtained for solids suspension at higher $C_{v}$ can be demonstrated better by using the inverse of $\varepsilon_{j s}$, as shown in Equation 4 . $\varepsilon_{j s}^{-1}=\frac{M_{s}}{P_{j s}}$

The $\varepsilon_{\text {js }}$ data shown in Figure 7a for 30PBT6 are used in plotting Figure 7b which shows $\varepsilon_{\mathrm{js}}{ }^{-1}$ versus $\mathrm{C}_{\mathrm{v}}$. The parameter $\varepsilon_{\mathrm{js}}{ }^{-1}$ represents the amount of solids that can be suspended per unit of impeller power input at $\mathrm{N}_{\mathrm{Js}}$ and its units are (kg solids suspended/W). With an increase in $\mathrm{C}_{\mathrm{v}}$, the $\varepsilon_{\mathrm{js}}{ }^{-1}$ value increases, reaches a maximum at $\left(\mathrm{C}_{\mathrm{v}}\right)_{\text {osc }}$ and decreases beyond that. It is interesting to note that, for each $\mathrm{W}$ of power input, about $4.5 \mathrm{~kg}$ of solids can be suspended at $\left(\mathrm{C}_{\mathrm{v}}\right)_{\text {osc }}=0.25 \mathrm{v} / \mathrm{v}$ whereas only $1.9 \mathrm{~kg}$ of solids can be suspended at $\mathrm{C}_{\mathrm{v}}=0.05 \mathrm{v} / \mathrm{v}$. These results indicate that the impeller energy efficiency in solid-liquid mixing vessels can be increased by operating them at higher solids concentrations (around $\left(\mathrm{C}_{\mathrm{v}}\right)_{\mathrm{osc}}$ ) than hitherto thought. It is also clear that operating the process at a lower solids concentration is not preferable because most of the impeller power input is utilized in pumping and moving the liquid without a proportional increase in solid suspension benefits, thereby leading to inadequate usage of tank infrastructure.

The value of $\left(\mathrm{C}_{\mathrm{v}}\right)_{\text {osc }}$ is most likely determined by the changes in slurry flow pattern in the tank at this solid concentration. The changes in slurry flow pattern can be identified from the impeller Reynolds number, which can be defined for solid-liquid agitated tank as: 
$\operatorname{Re}=\frac{\rho_{\text {slurry }} N_{j s} D^{2}}{\eta_{\text {slurry }}}$

where $\rho_{\text {slurry }}$ is the slurry density $\left(\mathrm{kg} / \mathrm{m}^{3}\right), \mathrm{N}_{\mathrm{js}}$ is just- suspension impeller speed (rps), D is the impeller diameter and $\eta_{\text {slurry }}$ is the slurry viscosity (Pa.s) at $\mathrm{N}_{\mathrm{js}}$. The precise calculation of an average Reynolds number in a solid-liquid mixing system is complex due to the fact that the homogeneity of the suspension varies with location and there is an axial/radial solids concentration gradient. In this instance, it is assumed that the particles are evenly distributed throughout the tank for the sake of calculating a characteristic Reynolds number. The slurry viscosity $\eta_{\text {slurry }}$ has been calculated using the equations 6 and 7 suggested by Thomas (1965) and Fedor (1975), respectively:

$$
\begin{aligned}
& \eta_{\text {slurry }}=\eta_{r}\left(1+2.5 C_{v}+10.05 C_{v}^{2}+0.0273 \exp \left(16.6 C_{v}\right)\right) \\
& \eta_{\text {slurry }}=\eta_{r}\left(1+\frac{1.25 C_{v}}{C_{b}-C_{v}}\right)^{2}
\end{aligned}
$$

In these equations, $\eta_{\mathrm{r}}$ is the viscosity of the carrier liquid and $\mathrm{C}_{\mathrm{b}}$ is the solid packing coefficient. The impact of solids loading on Re for impellers 30PBT6 under baffled and unbaffled conditions is shown in Figure 8 (a-b) (Can you remove the background colour in these figures?). It can be seen that Re decreases with increasing $C_{v}$, regardless of the baffle arrangement. It is also clear that, at $C_{v} \geq\left(C_{v}\right)_{o s c}$, Re value decreases below 10000 indicating the flow regime in the tank could be changing from turbulent to the transition flow regime as $\mathrm{C}_{\mathrm{v}}$ increases. $\mathrm{As} \mathrm{C}_{\mathrm{v}}$ approaches the 'maximum achievable solids concentration', $\left(\mathrm{C}_{\mathrm{v}}\right)_{\max }$, the flow regime changes into laminar. Under this condition, turbulence that is responsible for solid suspension will be dampened 
significantly thereby leading to excessive impeller power draw for achieving just-offbottom suspension.

\section{Effect of impeller type}

Specific impeller power input $\varepsilon_{\mathrm{js}}$ values as functions of solids concentration for DT6, 45PBT4 and A310 impellers under baffled conditions are shown in Figure 9a. The impellers were chosen to represent the three flow types namely, radial, mixed and axial flow, respectively. The results shown in this figure confirm that $\left(\mathrm{C}_{\mathrm{v}}\right)_{\mathrm{osc}}$ exists for all the three types of impellers. The $\left(C_{v}\right)_{\text {osc }}$ for DT6 is around $0.35 \mathrm{v} / \mathrm{v}$ whereas it is around $0.30 \mathrm{v} / \mathrm{v}$ for $45 \mathrm{PBT} 4$ and A310 impellers. The corresponding $\varepsilon_{\mathrm{js}}$ values at $\left(\mathrm{C}_{\mathrm{v}}\right)_{\mathrm{osc}}$ for

DT6, 45PBT4 and A310 impellers are 0.79, 0.23, and $0.21 \mathrm{~W} / \mathrm{kg}$ ( with $\varepsilon_{\mathrm{js}}{ }^{-1}$ values of $1.27,4.35,4.79 \mathrm{~kg} / \mathrm{W})$, respectively. It can be also seen that the effect of solids concentration on $\varepsilon_{\mathrm{js}}$ is more pronounced for DT6 as demonstrated by the U-shaped curve for this impeller. For all solids concentrations $(0.05-0.4 \mathrm{v} / \mathrm{v})$, $\varepsilon_{\mathrm{js}}$ values are the highest for DT6 followed by those for $45 \mathrm{PBT} 4$. A310 has the lowest $\varepsilon_{\text {js }}$ values. A relatively flat curve observed for A310 suggests that the effect of solids concentration on $\varepsilon_{\mathrm{js}}$ is not as significant for this impeller compared to other two impellers.

$\varepsilon_{j s}$ data for the above mentioned impellers under unbaffled conditions are shown in Figure $9 \mathrm{~b}$. In this case also, $\varepsilon_{\mathrm{js}}$ versus $\mathrm{C}_{\mathrm{v}}$ curves have a minimum corresponding to $\left(\mathrm{C}_{\mathrm{v}}\right)_{\text {osc }}$. It is interesting to see that, under unbaffled conditions, DT6, which has the highest power number $\left(\mathrm{N}_{\mathrm{p}}=5.6\right)$, is more energy efficient than the 45PBT4 $\left(\mathrm{N}_{\mathrm{p}}=1.22\right)$ and A310 $\left(\mathrm{N}_{\mathrm{p}}=0.32\right)$ irrespective of $\mathrm{C}_{\mathrm{v}}$. For a given $\mathrm{C}_{\mathrm{v}}$, DT6 has the lowest $\varepsilon_{\mathrm{js}}$ value over the whole range of $\mathrm{C}_{\mathrm{v}}$ used in this work (Figure $9 \mathrm{~b}$ ). While the difference in $\varepsilon_{\mathrm{js}}$ 
values for the three impellers is obvious at low $C_{v}(<0.20 \mathrm{v} / \mathrm{v})$, it becomes marginal as $\mathrm{C}_{\mathrm{v}}$ approaches $0.4 \mathrm{v} / \mathrm{v}$. At $\mathrm{C}_{\mathrm{v}}=0.40 \mathrm{v} / \mathrm{v}$, the three impellers have approximately the same $\varepsilon_{\mathrm{js}}$.

It has been well established in the literature that it is more energy efficient to employ lower power number impellers, for example axial flow impellers, for off-bottom solids suspension. Results shown in Figure 9a indicate that this is indeed true under baffled condition. However, under the unbaffled condition, the radial-flow impeller (DT6) becomes more energy efficient compared to mixed-flow (30PBT6) and axial-flow (A310) impellers. These results indicate that radial flow impellers with higher power numbers could be more energy efficient in suspending particles off the tank bottom. This trend is found to be true even for particles with different sizes as shown in this paper later.

\section{Effect of removal of baffles on $\varepsilon_{j s}$ reduction}

The $\varepsilon_{\text {js }}$ values for DT6, 45PBT4, and A310 under baffled and unbaffled conditions are shown in Figure 10 in the form of a bar graph for a few chosen $C_{v}$ values. The extent of $\varepsilon_{\text {js }}$ reduction due to the removal of baffles can be seen clearly from this graph. It is also clear that the reduction in $\varepsilon_{\mathrm{js}}$ is influenced by both impeller type and solids concentration. The reduction in $\varepsilon_{\mathrm{js}}$ is more pronounced for DT6. A significant $\varepsilon_{\mathrm{js}}$ reduction of up to $90 \%$ can be achieved for this impeller over a $C_{v}$ range of $0.16-0.4$ $\mathrm{v} / \mathrm{v}$ simply by removing the baffles (Figure 10a). Reduction in $\varepsilon_{\mathrm{js}}$ due to the removal of baffles is also observed for 45PBT4 and A310 but the extent of the reduction is lower compared to that for DT6. For 45PBT4, the extent of $\varepsilon_{\mathrm{js}}$ reduction is higher at higher $\mathrm{C}_{\mathrm{v}}$ which is contrary to what was observed for DT6 (Figure 10b). For A310, there is no 
clear trend in the extent of $\varepsilon_{\text {js }}$ reduction as a function of $C_{v}$ (Figure 10c). Based on these results, it may be concluded that the extent of $\varepsilon_{\mathrm{js}}$ reduction due to the removal of baffles is more significant for the radial flow impeller, followed by the mixed flow impeller. The impact for axial flow impeller seems to be relatively insignificant.

To analyse the reduction in impeller power consumption due to the removal of baffles, an impeller power number $\mathrm{N}_{\mathrm{p}}$ at $\mathrm{N}_{\mathrm{js}}$ was calculated according to equation (8):

$$
N_{p}=\frac{P_{j s}}{\rho_{\text {slurry }} N_{j s}^{3} D^{5}}
$$

where $\rho_{\text {slurry }}$ is the slurry density $\left(\mathrm{kg} / \mathrm{m}^{3}\right), \mathrm{P}_{\mathrm{js}}$ is the impeller power at $\mathrm{N}_{\mathrm{js}}(\mathrm{W}), \mathrm{N}_{\mathrm{js}}$ is just off-bottom suspension impeller speed (rps) and D is the impeller diameter (m). $N_{p}$ at $N_{j s}$ values for DT6, 45PBT4, A310 are shown in Figures 11a-c, respectively as a function of $\mathrm{C}_{\mathrm{v}} \cdot \mathrm{N}_{\mathrm{p}}$ at $\mathrm{N}_{\mathrm{js}}$ values under unbaffled condition are lower than those under baffled conditions regardless of $\mathrm{C}_{\mathrm{v}}$ and impeller type. These results also indicate that the extent of reduction in $\mathrm{N}_{\mathrm{p}}$ is most pronounced for DT6 followed by 45PBT4 and then A310.

The significant increase in impeller power reduction observed for DT6 due to the removal of baffles can be attributed to the reduction in energy dissipation on the vessel walls when the baffles are removed. In a fully baffled vessel, the liquid jet stream generated by the impeller rotation impinges directly on the tank wall leading to a reduction in its energy. In contrast, in an unbaffled tank, the liquid pumped by the impeller follows a tangential motion which causes it to circulate with minimum deflections off the tank wall, thereby leading to a reduction in drag loss and energy dissipation. Drewer et al. (1994) suggested that the absence of baffles in the lower part of the tank leads to an inward-spiralling flow pattern at the vessel base which sweeps 
any settled solids towards the centre of the base from where they are suspended due to the suction of a vortex formed under the impeller. In addition to the vortex under the impeller, solids suspension is probably helped also by the secondary circulation loop above the impeller especially for DT6. The suggestion is based on the observation in this work that slurry height $\left(\mathrm{H}_{\mathrm{S}}\right)$ at $\mathrm{N}_{\mathrm{js}}$ was always higher for DT6 than that for the axial flow impeller used in this work. Geisler et al., (1991) suggested that solids suspension in stirred vessels is dependent on particle pick-up off the tank bottom and continuous circulation of fresh liquid from the supernatant into the suspended slurry which ensures the particle suspension in the upper parts of the tank. This mechanism is very helpful in the suspension of slurries at higher solids concentrations. It can be anticipated that the flow circulation loop generated by a Rushton turbine contributes significantly to the entertainment of supernatant in the upper region of the vessel, leading to higher degree of suspension (i.e. High $\mathrm{H}_{\mathrm{s}}$ ) and improved energy efficiency (i.e. Low $\varepsilon_{\mathrm{js}}$ ).

\section{Effect of impeller dimensions (D/T, $t / W)$}

The effect of impeller diameter on $\varepsilon_{\mathrm{js}}$ is shown in Figures 12 (a) and (b) for baffled and unbaffled tanks, respectively. Experiments were conducted for a solid concentration range of $0.10-0.40 \mathrm{v} / \mathrm{v}$. Two A310 impellers of 0.16 and $0.20 \mathrm{~m}$ diameter, pumping downwards, were employed in the tests. Under unbaffled conditions, the effect of impeller diameter is marginal on $\varepsilon_{\mathrm{js}}$ at high solids concentrations $\left(\mathrm{C}_{\mathrm{v}}>0.30 \mathrm{v} / \mathrm{v}\right)$. This is consistent with results reported by Wu et al. (2009a, b). However, this finding has to be verified for other impeller types as well. From Figure 12(b), it is evident that, under unbaffled condition, an increase in impeller diameter leads to a decrease in $\varepsilon_{\mathrm{js}}$ $(\sim 0.2 \mathrm{~W} / \mathrm{kg})$ over the whole range of $\mathrm{C}_{\mathrm{v}}$ used in this work. The parallel curves for $\varepsilon_{\mathrm{js}}$ 
indicate that the ratio of $\varepsilon_{\text {js }}$ values for the two impellers with different diameters is fairly constant under unbaffled conditions.

The effect of blade thickness on $\varepsilon_{\mathrm{js}}$ is shown for 45PBT4 in Figure 13. It can be seen that the variation of $\varepsilon_{\mathrm{js}}$ with $\mathrm{C}_{\mathrm{v}}$ depends on blade thickness. At the minimum value of $\varepsilon_{\mathrm{js}},\left(\mathrm{C}_{\mathrm{v}}\right)_{\text {osc }}$ is $0.25 \mathrm{v} / \mathrm{v}$ for the impeller with the thinner blade $(\mathrm{t} / \mathrm{W}=0.062)$ but is 0.30 $\mathrm{v} / \mathrm{v}$ for the impeller with the thicker blade $(\mathrm{t} / \mathrm{W}=0.125)$. However, the $\varepsilon_{\mathrm{js}}$ value at $\left(\mathrm{C}_{\mathrm{v}}\right)_{\text {osc }}$ for both impellers is nearly the same. It is also clear that $\varepsilon_{\mathrm{js}}$ for the impeller with the thinner blade $(\mathrm{t} / \mathrm{W}=0.062)$ is lower for $\mathrm{C}_{\mathrm{v}}<0.27 \mathrm{v} / \mathrm{v}$ suggesting that this impeller is more efficient in this range. For $C_{v}>0.27 \mathrm{v} / \mathrm{v}$, the impeller with the thicker blade has a lower $\varepsilon_{\mathrm{js}}$, indicating that it is preferable to use the impeller with a thicker blade for high $\mathrm{C}_{\mathrm{v}}$.

In general, it can be concluded that $\mathrm{D} / \mathrm{T}$ does not have a big impact on the value of optimum solids concentration in a mixing tank. However, a slight change in t/W leads to shift in $\left(\mathrm{C}_{\mathrm{v}}\right)$ as.

\section{Effect of multiple impellers}

The $\varepsilon_{\text {js }}$ data for a dual A310 impeller and a single A310 impeller, both with $\mathrm{D} / \mathrm{T}=0.41$, are shown in Figure 14 as a function of $\mathrm{C}_{\mathrm{v}}$ under unbaffled conditions. It is interesting to note that the $\left(\mathrm{C}_{\mathrm{v}}\right)_{\text {osc }}$ for the dual A310 is similar to that of the single A310 impeller. At low $\mathrm{C}_{\mathrm{v}}(<0.3 \mathrm{v} / \mathrm{v})$, the presence of additional impeller leads to higher $\varepsilon_{\text {js }}$ due to the interaction of flow patterns generated by both impellers (Armenate and Li, 1993; Noceniti et al., 1988; Dutata and Pangakar, 1994). It can be also said that the increase in 
$\varepsilon_{\mathrm{js}}$ with an additional impeller is marginal $(<3 \%)$ at high $\mathrm{C}_{\mathrm{v}}$. This finding has not been verified for other impeller types or baffled condition.

It is reasonable that the dual impeller has higher $\varepsilon_{\text {js }}$ values at low $\mathrm{C}_{\mathrm{v}}$. In such cases, the lower impeller is responsible for solids suspension as reported by Armenante and Li (1993) and the upper impeller does not contribute much to just-off-bottom condition but contributes to additional impeller power draw thereby leading to higher $\varepsilon_{\mathrm{js}}$ values. At high $C_{v}$, the upper impeller would also contribute to solids suspension because of the enhanced pumping in the upper region of the tank which ensures even distribution of solid particles and therefore lower $\varepsilon_{\mathrm{js}}$ values.

\section{Effect of particle size}

Under unbaffled conditions, the influence of particle size on $\varepsilon_{\mathrm{js}}$ is shown in Figures 15 (a)-(c) for the three impellers used in this work. The three mean particle sizes used in this study were 90, 165 and $320 \mu \mathrm{m}$. It can be seen that coarser particles lead to higher $\varepsilon_{\mathrm{js}}$ values irrespective of the impeller type and solids concentration. These results indicate that it is more energy efficient to suspend a large number of small particles than a small number of large particles for the same amount of solids mass. This is a useful observation with a number of practical implications. For example, in the mineral processing industry, it is well known that the energy required to grind ore into fine particles is significantly high. However, when considering the overall energy usage, there is a benefit in handling slurries with fine particles because the reduction in $\varepsilon_{\mathrm{js}}$ for suspending fine particles in agitated vessels could partially compensate the higher energy spent in grinding ore into fine particles thereby leading to overall energy efficiency in the process. 
Drewer et al. (2000) evaluated the effect of particle size on specific power in a baffled tank and they reported that $\left(\mathrm{C}_{\mathrm{v}}\right)_{\text {osc }}$ is not affected by particle size but influenced by impeller type (Figure 16a). They also found that an increase in particle size results in higher power consumption at the just-suspended condition. The effects of particle size on $\left(\mathrm{C}_{\mathrm{v}}\right)_{\text {osc }}$ and the corresponding $\varepsilon_{\mathrm{js}}$ observed in this work are shown in Figure 16b. These results also imply that $\left(\mathrm{C}_{\mathrm{v}}\right)_{\text {osc }}$ is not affected by the impeller type for a given particle diameter $d_{p}$, under unbaffled condition. However, $\left(C_{v}\right)_{\text {osc }}$ was found to decrease with increase in $\mathrm{d}_{\mathrm{p}}$, irrespective of the impeller type. Also, $\varepsilon_{\mathrm{js}}$ increases dramatically with an increase in $d_{p}$. However, more experiments with a wide range of $d_{p}$ are required to confirm the relationship between $\varepsilon_{\mathrm{js}}$ and $\mathrm{C}_{\mathrm{v}}$ under baffled condition.

\section{Optimum Solids Concentration}

The specific power required for the complete suspension of solids for a range of solids concentrations and particle sizes has been discussed above. It has been confirmed that $\varepsilon_{j s}$ can be minimized by operating the agitated vessels at an optimum solids concentration, $\left(\mathrm{C}_{\mathrm{v}}\right)_{\text {osc }}$. Tables 3 and 4 summarise the values of $\left(\mathrm{C}_{\mathrm{v}}\right)_{\text {osc }}$ and the corresponding $\left(\varepsilon_{j s}\right)_{\text {min }}$ values for different impellers and particle sizes under baffled and unbaffled conditions, respectively.

Under baffled conditions, $\left(\mathrm{C}_{\mathrm{v}}\right)_{\text {osc }}$ is influenced by the impeller type and dimensions. However, a $\left(\mathrm{C}_{\mathrm{v}}\right)_{\text {osc }}=0.30 \mathrm{v} / \mathrm{v}$ is a representative value that can be used for all impellers used in this work. Under unbaffled conditions, it can be concluded that $\left(\mathrm{C}_{\mathrm{v}}\right)_{\text {osc }}$ is independent of impeller type but influenced by $d_{p}$. It is found that an increase in $d_{p}$ leads to a decrease in $\left(\mathrm{C}_{\mathrm{v}}\right)_{\text {osc }}$. 
The presence of a minimum $\varepsilon_{\mathrm{js}}$ in $\varepsilon_{\mathrm{js}}$ versus $C_{\mathrm{v}}$ graphs suggests that there are some advantages in operating the mixing tank at higher $C_{\mathrm{v}}$ than that which is generally used now. In the design of a new plant, an increase in $C_{\mathrm{v}}$ would result in the reduction of vessel and impeller sizes for a given mass throughput. As a consequence, capital costs can be reduced significantly. Also $\left(\mathrm{C}_{\mathrm{v}}\right)_{\mathrm{osc}}$ corresponding to the minimum $\varepsilon_{\mathrm{js}}$ has practical implications in the operation of slurry suspension vessels. Any solid-liquid mixing vessel designed based on the above criteria will lead to lower operating costs with optimum energy/power efficiency. Operating the solid-liquid mixing tanks with a dilute or relatively low $\mathrm{C}_{\mathrm{v}}$ is certainly not beneficial to industry from a practical point of view because operating costs will be unnecessarily higher due to insufficient usage of existing infrastructure. Also, low solids concentrations are not beneficial to mixing intensification, which is a means to significantly increase the yield per unit volume per unit time (Wu et al., 2010a).

The benefits of operating the solid-liquid mixing process at the $\left(\mathrm{C}_{\mathrm{v}}\right)_{\text {osc }}$ are yet to be fully exploited in industry. Wu et al., (2006, 2010) have considered various ways of improving the energy efficiency in a solid-liquid mixing tank by optimizing impeller design and tank geometry. It has been shown that significant gains in energy efficiency can be achieved by removing baffles, which are conventionally installed in most slurry tanks. However, a side effect of removing the baffles is increased mixing time (Wu et al. 2010b). This is usually not a problem in the mining/mineral processing industry where the time scales for reactions or mass transfer in slurry tanks are typically an order of magnitude greater than the mixing time. In some cases, even mixing is not required. An example is slurry holding tanks where the slurry is held to smooth out the fluctuations in the slurry flow rate which occur due to the variation of throughput in other equipment in 
the continuous process circuit. In addition to the removal of baffles, it is possible to further optimize the impeller power consumption by changing the impeller diameter, type, and blade thickness, which have been discussed in the previous section.

\section{A Simple Model}

A number of experiments were conducted in this study to evaluate the impact of different parameters on $\left(\mathrm{C}_{\mathrm{v}}\right)_{\text {osc }}$. It is of interest here to develop a simple mathematical model to predict $\left(\mathrm{C}_{\mathrm{v}}\right)_{\text {osc }}$ for different operating conditions.

The presence of solids can be expected to influence the impeller performance by modifying the suspension viscosity, local density and the vortex structure in the vicinity of the impeller blades (Kasat and Pandit, 2005). At higher loadings, the effect of solid particles on the impeller hydrodynamics becomes more significant, and thus influences the power consumption. Taking this into account, the following empirical correlation between power consumption and $\mathrm{C}_{\mathrm{v}}$ was proposed by Bubbico et al. (1998):

$$
P=N_{p}\left(1+k C_{v}\right) \rho_{w} N^{3} D^{5}
$$

where $\mathrm{P}(\mathrm{W})$ is the power required to satisfy the just-off-bottom condition, $\rho_{w}\left(\mathrm{~kg} / \mathrm{m}^{3}\right)$ is the density of water, $N_{p}\left(1+k C_{v}\right)$ was defined as the actual impeller power number, $\mathrm{C}_{\mathrm{v}}$ represents the volumetric solids concentration and the parameter $k$ was regarded as a measure of the additional energy dissipation due to the presence of solid particles (Bubbico et al., 1998). The mass of solids in the agitated vessel can be expressed as follows: 
$M_{s}=\rho_{s} V_{s}=\rho_{s} V C_{v}$

where $M_{s}$ is the mass of solids, $\rho_{s}$ represents the solid density, $V_{s}$ represents the volume of solids and V represents the total volume of liquid-solid system. Combining equations (9) and (10), we get:

$\varepsilon_{j s}=\frac{P}{M_{s}}=\left(N_{p} \frac{\rho_{w}}{V \rho_{s}} N^{3} D^{5}\right)\left(\frac{1}{C_{v}}+k\right)$

According to Zweitering (1958), the correlation between $\mathrm{N}_{\mathrm{js}}$ and $\mathrm{X}$ can be represented as follows:

$$
N_{j s}=S \frac{\nu^{0.1} d^{0.2}\left(g \Delta \rho / \rho_{L}\right)^{0.45} X^{a}}{D^{0.85}} \propto X^{a}
$$

where, $\mathrm{N}_{\mathrm{js}}$ is the impeller speed (rps), $\rho_{\mathrm{L}}$ is the liquid density $\left(\mathrm{kg} / \mathrm{m}^{3}\right), \Delta \rho$ is the difference in densities of solid and liquid $\left(\mathrm{kg} / \mathrm{m}^{3}\right)$, $\mathrm{d}$ is the solid mean particle diameter (m), D is the impeller diameter (m), $\mathrm{S}$ is a dimensional coefficient based on impeller type, $v$ is the kinematic viscosity $\left(\mathrm{m}^{2} \mathrm{~s}^{-1}\right)$ and $\mathrm{X}$ is the solids loading ratio (weight of solids $\times 100$ / weight of liquid).

But $\mathrm{X}$ is a function of $\mathrm{C}_{\mathrm{v}}$ as shown below:

$$
X=\left(\frac{\rho_{s}}{\rho_{w}}\right)\left(\frac{C_{v}}{1-C_{v}}\right) \times 100
$$


Combining equations (11), (12) and (13), we can get the following equation to determine the specific power dissipated by each impeller at $\mathrm{N}_{\mathrm{js}}$ :

$$
\varepsilon_{j s}=\frac{P}{M_{s}}=v^{0.1}\left(\frac{100 C_{v}}{1-C_{v}} \times \frac{\rho_{s}}{\rho_{w}}\right)^{3 a}\left(\frac{1}{C_{v}}+k\right)\left(\frac{S d^{0.2}\left(g \Delta \rho / \rho_{L}\right)^{0.45}}{D^{0.85}}\right)^{3}\left(\frac{N_{p} \rho_{w} D^{5}}{V \rho_{s}}\right)
$$

Based on Thomas's correlation (Honek et al., 2005), kinematic viscosity of the slurry can be estimated as a function of solids concentration using the following equation:

$$
v=\frac{\eta_{\text {slurry }}}{\rho_{\text {slurry }}}=\frac{\eta_{r}\left(1+2.5 C_{v}+10.05 C_{v}^{2}+0.0273 \exp \left(16.6 C_{v}\right)\right)}{\rho_{s} C_{v}+\rho_{w}\left(1-C_{v}\right)}
$$

Where $\eta_{\mathrm{r}}$ is the viscosity of the liquid phase. Thus, we have:

$$
\varepsilon_{j s}=G\left(\frac{100 C_{v} \rho_{s}}{\left(1-C_{v}\right) \rho_{w}}\right)^{3 a}\left(\frac{1}{C_{v}}+k\right) v^{0.1}
$$

where $G$ is the product of the last two groups (in brackets) in equation (14) and it is a constant for a given solid-liquid system, and tank and impeller geometries. Based on equation (16), $\varepsilon_{\mathrm{js}}$ can be regarded as a function of $\mathrm{C}_{\mathrm{v}}$ only for any given geometry due to the fact that the parameter $k$ is associated with the impeller type and particle size. This equation also indicates that $\varepsilon_{\mathrm{js}}$ is a measure of the additional energy dissipation due to the presence of the solid phase .

The exponent ' $a$ ' for low to medium $\mathrm{C}_{\mathrm{v}}(=0.09-0.20 \mathrm{v} / \mathrm{v})$ is approximately equal to 0.13 according to Zweitering (1958). It is assumed that $a \approx 0.13$ here from low to high 
$\mathrm{C}_{\mathrm{v}}$ although it was found by Wu et al. (2002) that ' $a$ ' is higher than 0.13 for very high $\mathrm{C}_{\mathrm{v}}(=0.4-0.52 \mathrm{v} / \mathrm{v})$.

The $\varepsilon_{\text {js }}$ values predicted using equation (16) as a function of $C_{v}$ are shown in Figure 17 for different impellers. For the sake of comparison, experimental values of $\varepsilon_{j s}$ for DT6 and 30PBT6 are also shown in Figure 17. The trends in predicted $\varepsilon_{\mathrm{js}}$ values confirm the presence of $\left(\mathrm{C}_{\mathrm{v}}\right)_{\text {osc }}$ at which $\varepsilon_{\mathrm{js}}$ is the minimum, regardless of the impeller type used. However, the predicted $\varepsilon_{\mathrm{js}}$ values exhibit a flat trend at higher $C_{\mathrm{v}}(0.40-0.60 \mathrm{v} / \mathrm{v})$ indicating that they are not valid in that range. This finding suggests that Zweitering's correlation has limitations and is not valid at high $\mathrm{C}_{\mathrm{v}}(>0.4 \mathrm{v} / \mathrm{v})$. The predicted $\varepsilon_{\mathrm{js}}$ values show that $\left(\mathrm{C}_{\mathrm{v}}\right)_{\text {osc }}$ is in the range of $0.20 \sim 0.25 \mathrm{v} / \mathrm{v}$ for the three impeller types used in this work (Table 5). Figures 17 (a-d) also show $\varepsilon_{\mathrm{js}}$ values predicted using different values of $S$ in Zwitering's equation. It is clear from these figures that $\varepsilon_{\mathrm{js}}$ is a function of $S$, but the value of $\left(C_{V}\right)_{\text {osc }}$ is not affected by $S$ as can be seen from equation (12). It may be concluded from Figure 17 that $S \approx 2$ is probably the appropriate value to predict $\varepsilon_{\text {js }}$ values for the system used in this study at different $\mathrm{C}_{\mathrm{v}}$. (Can you really use a single S value for all impellers? Certainly this question will be asked by the reviewer).

From the results shown above, it can be said that the model equation (16) predicted $\left(\mathrm{C}_{\mathrm{v}}\right)_{\text {osc }}$ satisfactorily. However, the flow pattern in the suspension was assumed to be turbulent in developing this equation even at high $C_{v}$ because equation (9) was used in estimating Re. Further improvements in the equation can be made by considering the changes in the flow pattern as $\mathrm{C}_{\mathrm{v}}$ increases. 


\section{Particle Dispersion at $\mathbf{N}_{\mathrm{js}}$}

A typical solids concentration profile measured by Hicks et al. (1997) at $\mathrm{N}_{\mathrm{js}}$ is shown in Figure 18. The system consisted of a Chemineer HE-3 impeller and glass beads with a mean diameter of $200 \mu \mathrm{m}$ and a density of $2500 \mathrm{~kg} / \mathrm{m}^{3}$. The axial solids concentration profile shown in the graph indicates that the solids concentration is relatively constant throughout much of the slurry, while rapidly falling to zero at around the cloud height, $\mathrm{H}_{\mathrm{s}}$. Hicks et al. pointed out that similar behaviour can be found at other operating conditions and suggested that 'although the cloud height does not give the most detailed information possible, it does provide a sound qualitative basis for design'. They believed that dispersion of particles can be quantified by the normalized slurry cloud height $\left(\mathrm{H}_{\mathrm{s}} / \mathrm{H}\right)$, where $\mathrm{H}_{\mathrm{s}}$ represents the slurry cloud height $(\mathrm{m})$ and $\mathrm{H}$ is the liquid height (m). Based on the above discussion, the following criteria should be met to maintain a homogeneous condition in solid-liquid mixing which is desirable in many industrial applications such as catalytic reactors, slurry holding tanks etc.,:

$$
\begin{aligned}
& \mathrm{H}_{\mathrm{s}}=\mathrm{H}, \\
& \mathrm{H}_{\mathrm{B}}=0 .
\end{aligned}
$$

Experimental values of normalized bed heights $\left(\mathrm{H}_{\mathrm{s}} / \mathrm{H}\right)$ at $\mathrm{N}_{\mathrm{js}}$ for DT6, 30PBT6 and A310 impellers are shown for selected $C_{v}$ in Figures 19 a-c, respectively. Of these three impellers, DT6 has the best performance in dispersing the particles at $\mathrm{N}_{\mathrm{js}}$ as it can lead to nearly complete dispersion of particles $\left(\mathrm{H}_{\mathrm{s}} / \mathrm{H}=1\right)$ from low- to high $\mathrm{C}_{\mathrm{v}}(0.15 \sim 0.40$ $\mathrm{v} / \mathrm{v}$ ), regardless of the baffle arrangement. Figures $19 \mathrm{~b}$ and c suggest that the removal of baffles plays an important role in improving the particle dispersion for 30PBT6 and A310 impellers, as higher $\mathrm{H}_{\mathrm{s}} / \mathrm{H}$ values are obtained under unbaffled conditions. It can be also seen from Figure 19b that it is not possible to fully disperse the particles throughout the tank at $\mathrm{N}_{\mathrm{js}}$ by 30PBT6, regardless of $\mathrm{C}_{\mathrm{v}}$ used. In contrast, full dispersion 
of particles is achieved by A310 under unbaffled conditions although at relatively lower $\mathrm{C}_{\mathrm{v}}=0.25$ and $0.30 \mathrm{v} / \mathrm{v}$ (Figure 19c). These results lead us to conclude that the removal of baffles helps not only in improving the off-bottom suspension of solids but also in dispersing them better.

\section{Optimized Tank Design}

A case example is shown in Figure 20 to illustrate the benefits of adopting some of the optimization methods highlighted in the earlier sections of this paper.

Figure 20a shows a pre-modified design in which the solid-liquid mixing tank was equipped with an A310, a widely used axial flow impeller for solids suspension. To the authors' best knowledge, operating solid-liquid mixing tanks with relatively low solids concentrations $\left(\mathrm{C}_{\mathrm{v}}<0.20 \mathrm{v} / \mathrm{v}\right)$ is still common practice in mineral industries. Based on this, a low solids concentration $\left(C_{v}=0.10 \mathrm{v} / \mathrm{v}\right)$ was chosen for this example. The premodified design (Figure 20a) had four baffles as baffled tanks are generally considered to be 'standard' in solid-liquid mixing and a considerable effort has been made in studying impeller power requirement for solids suspensions in baffled tanks (Nienow 1968; Drewer et al., 1994; Bubbico et al., 1998; Raghavo Rao et al., 1998; Wu et al., 2002)., Poor utilization of tank volume can be seen clearly in the pre-modified system from a relatively low value for $\mathrm{H}_{\mathrm{s}} / \mathrm{H}(=0.68)$. Values of other important operational parameters are shown in Figure 20a.

Details of a new (modified) design are shown in Figure 20b. The tank had DT6 and no baffles. The tank was operated at a higher solids concentration $\left(\mathrm{C}_{\mathrm{v}}=0.33 \mathrm{v} / \mathrm{v}\right)$ but it required relatively lower $\mathrm{N}_{\mathrm{js}}(=169 \mathrm{rpm})$. It can be noted that the degree of particle 
dispersion has improved significantly as indicated by a larger $\mathrm{H}_{\mathrm{s}} / \mathrm{H}$ value $(\sim 1)$ obtained in this case. From this observation, it is quite evident that greater energy efficiency in this case has been achieved by operating the tank at higher $\mathrm{C}_{\mathrm{v}}$ but using a lower $\varepsilon_{\mathrm{js}}=$ $0.13 \mathrm{~W} / \mathrm{kg}$ simply by changing the impeller type and removing the baffles. In other words, a substantial increase in $\mathrm{C}_{\mathrm{v}}$ (3.3 times) has been achieved with an $18 \%$ reduction in $\varepsilon_{\mathrm{js}}$ with minimum design changes. In comparison, the pre-modified design required a much higher $\varepsilon_{\mathrm{js}}(=0.37 \mathrm{~W} / \mathrm{kg})$ for suspending lower $\mathrm{C}_{\mathrm{v}}=0.10 \mathrm{v} / \mathrm{v}$. The changes mentioned above helped in minimizing the capital cost which otherwise would have included the cost of retrofitting gear box for a speed upgrade.

The overall benefits of 'process intensification' of solid-liquid mixing tanks which include changing the tank design and operating the tank with an increased solids concentration can be thus summarized as follows: a) maintaining (or even reduction) of impeller power consumption and agitator speed; b) increase in yield or throughput; c) improvement in energy efficiency; d) improvement in particle dispersion.

\section{Conclusions}

The specific impeller power required for the off-bottom suspension of solids was studied over a range of solids concentrations and particle sizes. It is established that the specific impeller power at $\mathrm{N}_{\mathrm{js}}$ expressed on the basis of total volume of suspension $\left(\mathrm{P}_{\mathrm{js}} / \mathrm{V}\right)$ increases rapidly with increase in solids concentration for $\mathrm{C}_{\mathrm{v}}>0.30 \mathrm{v} / \mathrm{v}$. Nevertheless, when the specific power input is considered in terms of the mass of solids suspended $\left(\varepsilon_{\mathrm{js}}=\mathrm{P}_{\mathrm{js}} / \mathrm{M}_{\mathrm{s}}\right)$, it decreases with solids concentration up to a critical value and 
increases beyond that. This result is observed for radial (DT6), mixed (30PBT6), and axial (A310) flow impellers used in this work under baffled and unbaffled conditions.

It is also found that $\varepsilon_{\text {js }}$ can be minimized by operating the vessel at a suitable solids concentration in the range of $0.20-0.35 \mathrm{v} / \mathrm{v}$ for the impeller types and baffling conditions used in this study. Under baffled conditions, the optimum solids concentration $\left(\left(\mathrm{C}_{\mathrm{v}}\right)_{\text {osc }}\right)$ is influenced by the impeller type and impeller dimension. Under unbaffled conditions, however, $\left(\mathrm{C}_{\mathrm{V}}\right)_{\mathrm{osc}}$ is independent of particle size but influenced by impeller type.

Higher power number radial flow impellers are found to be more energy efficient than lower power number axial flow impellers for suspending fine particles under unbaffled conditions. It appears that the effect of removing baffles is more significant at lower $\mathrm{C}_{\mathrm{v}}$ for the radial flow impeller (DT6) because it leads to a significant reduction in $\varepsilon_{\text {js. }}$ At higher $C_{v}$, there is also a reduction in $\varepsilon_{\text {js }}$ for DT6 due to the removal of baffles but the extent of the reduction is not as significant as that at the low solids concentration. Of all the impellers used, the radial flow impeller (DT6) is the most sensitive to the removal of baffles irrespective of $\mathrm{C}_{\mathrm{v}}$. These results imply that DT6 is the most energy efficient under unbaffled conditions compared to the axial- and mixed flow impellers tested.

A simple mathematical model based on Zweitering's correlation for $\mathrm{N}_{\mathrm{js}}$ is found to predict the optimum solids concentration satisfactorily. It is suggested that the removal of baffles helps not only in improving the off-bottom suspension of solids but also in dispersing them more effectively. 


\section{Acknowledgements}

The research was supported financially by Fluids Engineering Group, CSIRO, Australia. 


\section{Nomenclature}

B baffle width (m)

$C_{v} \quad$ solids volume concentration (v/v)

$\left(C_{v}\right)_{\max } \quad$ maximum solids volume concentration $(\mathrm{v} / \mathrm{v})$

$\left(\mathrm{C}_{\mathrm{v}}\right)_{\text {osc }}$ optimum solids concentration $(\mathrm{v} / \mathrm{v})$

$d \quad$ particle size $(\mathrm{mm})$

$D \quad$ impeller diameter (m)

$H \quad$ liquid level (m)

$H_{B} \quad$ settled bed height (m)

$H_{\mathrm{S}} \quad$ slurry cloud height (m)

$\mathrm{k} \quad$ impeller constant in equation 9

$\mathrm{M}_{\mathrm{s}} \quad$ mass of solids $(\mathrm{kg})$

$N \quad$ impeller speed (rev/s, rpm)

$N_{j s} \quad$ impeller speed for just-off-bottom solids suspension (rpm)

$N_{P} \quad$ power number

$M_{s} \quad$ solids mass $(\mathrm{kg})$

$P \quad$ power $(\mathrm{W})$

$P_{j s} \quad$ agitator power for achieving just-off-bottom solids suspension (W)

$\mathrm{S}$ dimensional coefficient in equation 12

$T \quad$ tank diameter (m)

$\mathrm{t} \quad$ blade thickness (m)

$V \quad$ tank volume $\left(\mathrm{m}^{3}\right)$

$\mathrm{W} \quad$ blade width (m)

$\mathrm{X} \quad$ solids loading ratio

$\varepsilon_{\mathrm{js}} \quad$ specific power input, agitator power per unit solids mass at the just-off-bottom solids suspension condition $\left(\mathrm{P}_{\mathrm{j} s} / \mathrm{M}_{\mathrm{s}}\right)$, $(\mathrm{W} / \mathrm{kg})$

$\varepsilon_{j s}^{-1} \quad$ mass of solids suspended per Watt at the just-off-bottom solids suspension condition $\left(\mathrm{M}_{\mathrm{s}} / \mathrm{P}_{\mathrm{js}}\right)$, $(\mathrm{kg} / \mathrm{W})$; power efficiency factor.

$\left(\varepsilon_{j \mathrm{~s}}\right)_{\min }$ specific power consumption at $\left(\mathrm{C}_{\mathrm{v}}\right)_{\text {osc }}(\mathrm{W} / \mathrm{kg})$

$\rho_{\mathrm{l}} \quad$ liquid density $\left(\mathrm{kg} / \mathrm{m}^{3}\right)$

$\rho_{\text {Sl }} \quad$ solid density $\left(\mathrm{kg} / \mathrm{m}^{3}\right)$

$\rho_{\mathrm{Sl}} \quad$ slurry density $\left(\mathrm{kg} / \mathrm{m}^{3}\right)$

$\eta_{r} \quad$ viscosity of carrier fluid (Pa.s)

$\eta_{\text {slurry }}$ viscosity of slurry (Pa.s) 


\section{References}

Armenante PM, Li T. Minimum Agitation Speed for Off-Bottom Suspension of Solids in Agitated Vessels Provided with Multiple Flat-Blade Impellers. AIChE Symp. Ser. Part II. 1993; 89:105-111.

Bubbico R, Di Cave S, Mazzarotta B. Agitation Power for Solid-Liquid Suspensions Containing Large Particles. Canadian Journal of Chemical Engineering. 1998; 76:428432.

Chapman CM, Nienow AW, Cooke M, Middleton JC. Particle-Gas-Liquid Mixing in Stirred Vessels. Part II: Gas-Liquid Mixing. Chem. Eng. Res. Des. 1983a; 61: 82-95.

Chapman CM, Nienow AW, Cooke M, Middleton JC. Particle-Gas-Liquid Mixing in Stirred Vessels. Part III: Three Phase Mixing. Chem. Eng. Res. Des.1983b; 61: 167-181.

Drewer GR, Ahmed N, Jameson GJ. Suspension of High Concentration Solids in Mechanically Stirred Vessels. IChemE Symp. Ser. 1994; 136:41-48.

Drewer, GR, Ahmed, N, Jameson, GJ. An Optimum Concentration for the Suspension of Solids in Stirred Vessels. Mixing and Crystallization, Kluwer Academic Publishers, Netherlands. 2000.

Dutta NN, Pangarkar VG.Critical Impeller Speed for Solid Suspension in MultiImpeller Agitated Contactors: Solid-Liquid System. Chem. Eng. Comm. 1995; 137:135146.

Fedors, R.F. Variability of Ultimate Properties of Elastomer. Journal of Applied Polymer. 1975; 19: 787-790.

Geisler RK, Buurman C, Mersmsann AB. Concept for Scale-up of Solids Suspension in

Stirred Tanks. In Proc. $7^{\text {th }}$ European Conf. on Mixing, Brugge, BHRA, Cranfiled. 1991; 451-459.

Hicks MT, Myers KJ, Bakker A. Cloud Height in Solids Suspension Agitation. Chem. Engg. Comm. 1997; 160: 137-155.

Honek, T., Hausnerova, B., Saha, P., 2005. Relative viscosity models and their application to capillary flow data of highly filled hard-metal carbide powder compounds. Polymer Composites, Doi 10.1002/pc.20067 
Kasat GR, Pandit A. Review on Mixing Characteristics in Solid-Liquid and SolidLiquid-Gas Reactor Vessel. Canadian Journal of Chemical Engineering. 2005; 83:618643.

Nienow AW. The Suspension of Solid Particles. In N. Harnby, MF Edwards and AW Nienow, editors. Mixing in the Process Industries. $2^{\text {nd }}$ edition, Butterworths, London, U.K. ,1992.

Nienow AW. Suspension of Solid Particles in Turbine Agitated Baffled Vessels. Chem. Eng. Sci. 1968; 23:1453-1459.

Nocentini MF, Magell F, Pasquali G. On the Modeling of the Gas Behaviour of GasLiquid Vessels Stirred with Multiple Impellers. In $6^{\text {th }}$ European Conference on Mixing, Pavia, Italy. 1988.

Raghavo Rao KSMS, Rewatkar VB, Joshi JB. Critical Impeller Speed for Solid Suspension in Mechanically Agitated Contactors. AIChE. 1998;34:1332-1340.

Thomas, D.G. Transport Characteristics of Suspension: VIII. A Note On the Viscosity of Newtonian Suspensions of Uniform Spherical Particles. Journal of Colloid Science. 1965; 20: 267-277.

Wang, S., Boger, D., Wu, J.. Energy Efficient Solids Suspension in an Agitated VesselWater Slurry. Chemical Engineering Science. 2012. 74, 233-243.

Wu J, Zhu YG, Pullum L. Suspension of High Concentration Slurry. AIChE. 2002; 48: 1349-1352.

Wu J, Nguyen B, Graham L. Energy Efficient High Solids Loading Agitation for the Mineral Industry. Canadian Journal of Chemical Engineering. 2010a; 88:287-294.

Wu J, Nguyen B, Graham L. Mixing Intensification for the Mineral Industry. Canadian Journal of Chemical Engineering, 2010b; 88: 447-454.

Zwietering TN. Suspending of Solid Particles in Liquid by Agitators. Chemical Engineering Science. 1958; 8: 244-253. 


\section{Tables}

Table 1 Particles used in the experiments

\begin{tabular}{cccc}
\hline & $\begin{array}{c}\mathrm{d}_{10} \\
(\mu \mathrm{m})\end{array}$ & $\begin{array}{c}\mathrm{d}_{50} \\
(\mu \mathrm{m})\end{array}$ & $\begin{array}{c}\mathrm{d}_{90} \\
(\mu \mathrm{m})\end{array}$ \\
\hline Particle A & 70 & 90 & 100 \\
Particle B & 110 & 165 & 235 \\
Particle C & 260 & 320 & 480 \\
\hline
\end{tabular}


Table 2 Impeller specifications and power number $\left(\mathrm{N}_{\mathrm{p}}\right)$ measured at nominal $\mathrm{C} / \mathrm{T}=1 / 3$, $\mathrm{D}=390 \mathrm{~mm}$

\begin{tabular}{llccccc}
\hline $\begin{array}{l}\text { Impeller } \\
\text { ID }\end{array}$ & \multicolumn{1}{c}{ Full Name } & $\begin{array}{c}\text { Flow } \\
\text { Pattern }\end{array}$ & $\begin{array}{c}\text { No. of } \\
\text { Blades }\end{array}$ & W/D & D/T & $\begin{array}{c}\text { Power } \\
\text { No. }\left(\mathrm{N}_{\mathrm{p}}\right)\end{array}$ \\
\hline DT6 & 6-bladed radial disc turbine & Radial & 6 & 0.125 & 0.41 & 5.60 \\
45PBT4 & $4^{\circ}$ pitched 4-bladed turbine & Mixed & 4 & 0.125 & 0.41 & 1.22 \\
45PBT4 & $4^{\circ}$ pitched 4-bladed turbine & Mixed & 4 & 0.062 & 0.41 & 1.22 \\
A310 & Lightnin hydrofoil impeller & Axial & 3 & 0.125 & 0.46 & 0.32 \\
A310 & Lightnin hydrofoil impeller & Axial & 3 & 0.125 & 0.41 & 0.32 \\
30PBT6 & 30 ${ }^{\circ}$ pitch 6-bladed turbine & Axial & 6 & 0.125 & 0.41 & 0.72 \\
\hline
\end{tabular}

(T: tank diameter; D: impeller diameter; W: blade width) 
Table 3 Optimum solids concentration and corresponding $\left(\varepsilon_{j s}\right)_{\text {min }}$ under baffled condition. $d_{p}=120 \mu \mathrm{m}$.

\begin{tabular}{|c|c|c|c|c|}
\hline & $\begin{array}{r}\text { Il } \\
\text { spec }\end{array}$ & $\begin{array}{l}\text { eller } \\
\text { cations }\end{array}$ & $\left(\mathrm{C}_{\mathrm{v}}\right)_{\mathrm{osc}}$ & $\left(\varepsilon_{j \mathrm{~s}}\right)_{\mathrm{mi}}$ \\
\hline & $\mathrm{D} / \mathrm{T}$ & $\begin{array}{l}\text { W/D } \\
(\%)\end{array}$ & $(\% \mathrm{v} / \mathrm{v})$ & (W/kg) \\
\hline DT6 & 0.41 & 9.4 & 35 & 0.76 \\
\hline A310 & 0.46 & & 30 & 0.23 \\
\hline A310 & 0.41 & & 27 & 0.21 \\
\hline 45РBT4 & 0.41 & 4.7 & 30 & 0.23 \\
\hline 45РBT4 & 0.41 & 9.4 & 25 & 0.22 \\
\hline 30РВТ6 & 0.41 & 9.4 & 25 & 0.22 \\
\hline
\end{tabular}


Table 4 Optimum solids concentration and the corresponding $\left(\varepsilon_{j s}\right)$ min under unbaffled condition

\begin{tabular}{llccc}
\hline & Impeller specification & $\begin{array}{c}\mathrm{d}_{\mathrm{p}} \\
(\mu \mathrm{m})\end{array}$ & $\begin{array}{c}\left(\mathrm{C}_{\mathrm{v}}\right)_{\text {osc }} \\
(\mathrm{v} / \mathrm{v})\end{array}$ & $\begin{array}{c}\left(\varepsilon_{j s}\right)_{\min } \\
(\mathrm{W} / \mathrm{kg})\end{array}$ \\
\hline DT6 & $\mathrm{D} / \mathrm{T}=0.41 ; \mathrm{W} / \mathrm{D}=9.4 \%$ & 120 & 33 & 0.13 \\
DT6 & $\mathrm{D} / \mathrm{T}=041 ; \mathrm{W} / \mathrm{D}=9.4 \%$ & 165 & 25 & 0.14 \\
DT6 & $\mathrm{D} / \mathrm{T}=0.41 ; \mathrm{W} / \mathrm{D}=9.4 \%$ & 320 & 20 & 0.44 \\
A310 & $\mathrm{D} / \mathrm{T}=0.41$ & 120 & 33 & 0.18 \\
A310 & $\mathrm{D} / \mathrm{T}=0.46$ & 120 & 33 & 0.17 \\
Dual A310 & $\mathrm{D} / \mathrm{T}=0.41$ & 120 & 33 & 0.17 \\
A310 & $\mathrm{D} / \mathrm{T}=0.41$ & 165 & 25 & 0.23 \\
A310 & $\mathrm{D} / \mathrm{T}=0.41$ & 320 & 20 & 0.62 \\
45PBT4 & $\mathrm{D} / \mathrm{T}=0.41 ; \mathrm{W} / \mathrm{D}=9.4 \%$ & 120 & 33 & 0.12 \\
45PBT4 & $\mathrm{D} / \mathrm{T}=0.41 ; \mathrm{W} / \mathrm{D}=9.4 \%$ & 165 & 25 & 0.17 \\
45PBT4 & $\mathrm{D} / \mathrm{T}=0.41 ; \mathrm{W} / \mathrm{D}=9.4 \%$ & 320 & 20 & 0.52 \\
\hline
\end{tabular}

Impeller clearance to tank diameter ratio: $\mathrm{C} / \mathrm{T}=1 / 3$ 
Table 5 Optimum solids concentration: predicted results based on equation (16), with baffled installed.

\begin{tabular}{lcccccc}
\hline & \multicolumn{2}{c}{ Rushton Turbine } & \multicolumn{2}{c}{ Pitched Turbine } & \multicolumn{2}{c}{ Hydrofoil } \\
\hline & Prediction1 & Prediction2 & Prediction3 & Prediction4 & Prediction5 & Prediction6 \\
\hline $\mathrm{D}(\mathrm{mm})$ & 100 & 150 & 100 & 150 & 100 & 150 \\
$\mathrm{~N}_{\mathrm{p}}$ & 3.338 & 3.502 & 1.582 & 1.391 & 0.735 & 0.734 \\
$\mathrm{k}$ & 2.794 & 2.447 & 2.227 & 1.315 & 1.603 & 1.169 \\
$\left(\mathrm{C}_{\mathrm{v}}\right)_{\text {osc }}$ & 0.20 & 0.25 & 0.25 & 0.25 & 0.25 & 0.25 \\
$($ predicted*) & & & & & & 0.30 \\
$\left(\mathrm{C}_{\mathrm{v}}\right)_{\text {osc }}$ & 0.35 & 0.35 & $0.25 \sim 0.30$ & $0.25 \sim 0.30$ & & 0.30 \\
$($ Experimental $)$ & & & & & & \\
\hline
\end{tabular}

*These values were attained based on Fig. 17 


\section{Figures}

\section{Captions}

Figure 1 Schematic diagram of the experimental set-up used in this study.

Figure 2 Impellers. (a) radial flow impeller: DT6, (b) mixed flow impeller: 45PBT4. (c) axial flow impeller: A310

Figure 3 Visual method to determine $N_{j s}$ in solid-liquid mixing vessels. (a) $N>$ $\mathrm{N}_{\mathrm{js}}$, homogenous suspension, $\mathrm{H}_{\mathrm{s}}=\mathrm{H}$; (b) $\mathrm{N}=\mathrm{N}_{\mathrm{js}}, \mathrm{H}_{\mathrm{B}}=0$; (c) $\left(\mathrm{N}_{\mathrm{js}}-\mathrm{N}\right) \approx$ 2 rpm, $\mathrm{H}_{\mathrm{B}}>0$; (d) $\mathrm{N}<<\mathrm{N}_{\mathrm{js}}, \mathrm{H}_{\mathrm{B}}>0$.

Figure $4 \mathrm{H}_{\mathrm{B}}$ vs. $\mathrm{N}$ in a baffled tank, $\mathrm{N}_{\mathrm{js}}$ determination at different solids concentrations. Impeller: 30PBT6.

Figure 5 (a) Variation of specific impeller power $\left(\mathrm{P}_{\mathrm{js}} / \mathrm{V}\right)$ with increase in solids concentration. Solids: glass particles of $\mathrm{d}_{50}=0.165 \mathrm{~mm}$. Impellers: 30PBT6 and A310 (Wang et al., 2012).

Figure 6 Effect of solids concentration on viscosity (viscosity calculations were based on the correlations reported in the paper by Honek et al., (2005)).

Figure 7 (a) Variations of specific power $\left(\varepsilon_{\mathrm{js}}=\mathrm{P}_{\mathrm{js}} / \mathrm{M}_{\mathrm{s}}\right)$ with solids concentration when beffled. Impeller: 30PBT6. solids: glass particles of $\mathrm{d}=0.165$ mm. (b) Variation of $\varepsilon_{\mathrm{js}}{ }^{-1}$ values with solids concentration when baffled. Impeller: 30PBT6.

Figure 8 Effect of solids concentration on Reynolds number (Re) at $\mathrm{N}_{\mathrm{js}}$. (a) 30PBT6, Under baffled condition; (b) 30PBT6, unbaffled; (c) A310, Under baffled condition; (d) A310, unbaffled. (viscosity calculations were based on the correlations reported in the paper by Honek et al., (2005)).

Figure 9 Effect of impeller type, solids: glass particles of $\mathrm{d}_{50}=0.165 \mathrm{~mm}$, impellers: DT6, 45PBT4, A310. (a) Effect of impeller type on $\varepsilon_{\mathrm{js}}$, when baffled; (b) Effect of impeller type on $\varepsilon_{j s}^{-1}$, when baffled; (c) Effect of impeller type on $\varepsilon_{\mathrm{js}}$, when unbaffled; (d) Effect of impeller type on $\varepsilon_{j s}^{-1}$, when unbaffled.

Figure 10 Effect of baffles removal on $\varepsilon_{\mathrm{js}}$ reductions for impellers: DT6, 45PBT4, A310 respectively. Solids: glass particles of $d_{50}=0.165 \mathrm{~mm}$. (a) DT6 $\left(\mathrm{N}_{\mathrm{p}}=5.60\right)$; (b) 45PBT4 ( $\left.\mathrm{N}_{\mathrm{p}}=1.22\right)$; (c) A310 $\left(\mathrm{N}_{\mathrm{p}}=0.32\right)$.

Figure 11 Effect of baffles removal on power number for impellers: DT6, 45PBT4, A310. Solids: particles of $\mathrm{d}_{50}=0.165 \mathrm{~mm}$. (a) DT6; (b) 45PBT4; (c) A310. 
Figure 12 Effect of impeller diameter on $\varepsilon_{\mathrm{js}}$, solids: glass particles of $\mathrm{d}=0.165 \mathrm{~mm}$. Impeller: A310. (a) Baffled; (b) Unbaffled.

Figure 13 Effect of blade thickness on $\varepsilon_{\text {js }}$, solids: glass particles of $\mathrm{d}=0.165 \mathrm{~mm}$ when baffled. Impeller: 45PBT4.. ( $\mathrm{t}=$ impeller thickness. $\mathrm{W}=$ impeller width)

Figure 14 Effect of dual impellers on $\varepsilon_{\mathrm{js}}$, solids: glass particles of $\mathrm{d}=0.165 \mathrm{~mm}$ when baffled. Impeller: A310.

Figure 15 Effect of particle size on $\varepsilon_{\mathrm{js}}$, solids: glass particles when baffled. (a) DT6; (b) 45PBT4; (c) A310.

Figure 16 Effect of particle size on optimum solids concentration $\left(\mathrm{C}_{\mathrm{v}}\right)_{\text {osc }}$ and corresponding $\varepsilon_{\mathrm{js}}$. (a) Baffled (Drewer et al., 2000), (b) Unbaffled

Figure $17 \quad \varepsilon_{j s}$ values predicted using equation 7 (a). vs. $C_{v}, a=0.13, \rho_{\mathrm{w}}=$ $1000 \mathrm{~kg} / \mathrm{m}^{3}, \rho_{\mathrm{s}}=2500 \mathrm{~kg} / \mathrm{m}^{3}$. Refer to table 6 for power number $\mathrm{N}_{\mathrm{p}}$ and $\mathrm{k}$ values. (a) $S=1$; (b) $S=2$; (c) $S=3$; (d) $S=4$

Figure 18 Typical axial solids concentration profile (Hicks et al., 1997), impeller: HE-3, $\mathrm{d}_{\mathrm{p}}=200 \mu \mathrm{m}, \mathrm{D} / \mathrm{T}=0.35, \mathrm{C} / \mathrm{T}=0.25, \mathrm{H} / \mathrm{T}=1$, solids mass fraction $=0.116$.

Figure 19 Ratio of cloud and liquid heights at $\mathrm{N}_{\mathrm{js}}\left(\mathrm{H}_{\mathrm{S}} / \mathrm{H}\right)$ vs. $\mathrm{C}_{\mathrm{v}}$ when baffled and unbaffled: (a) radial flow impeller: DT6; (b) mixed flow impeller: 30PBT6; (c) axial flow impeller: A310. $\mathrm{d}_{50}=90 \mu \mathrm{m}$

Figure 20 Design modification for an agitated reactor: (a) existing design, $\mathrm{C}_{\mathrm{v}}=$ $0.10 \mathrm{v} / \mathrm{v}$; (b) modified design, $\mathrm{C}_{\mathrm{v}}=0.33 \mathrm{v} / \mathrm{v} . \mathrm{d}_{50}=90 \mu \mathrm{m}$ 


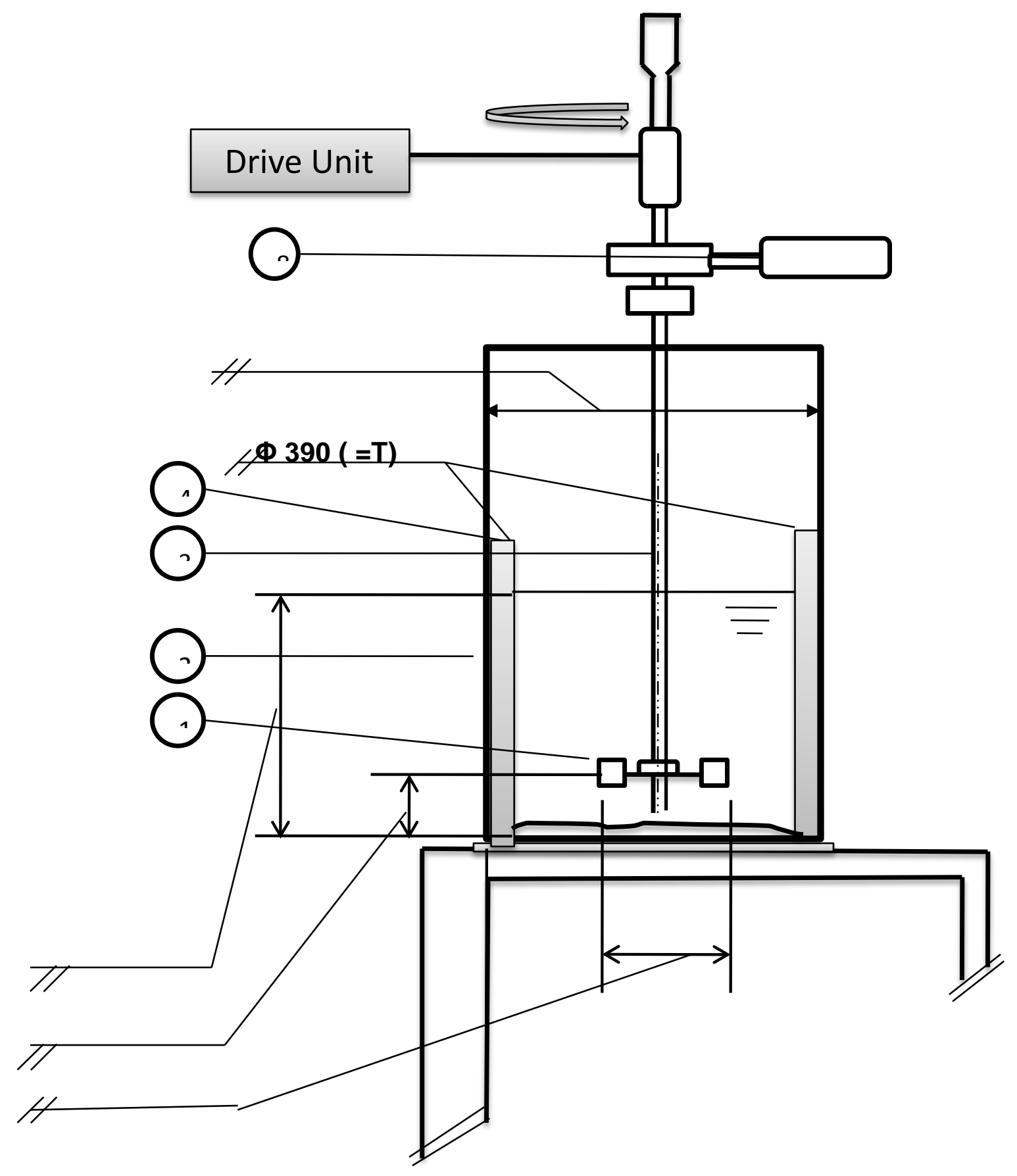

Figure 1 

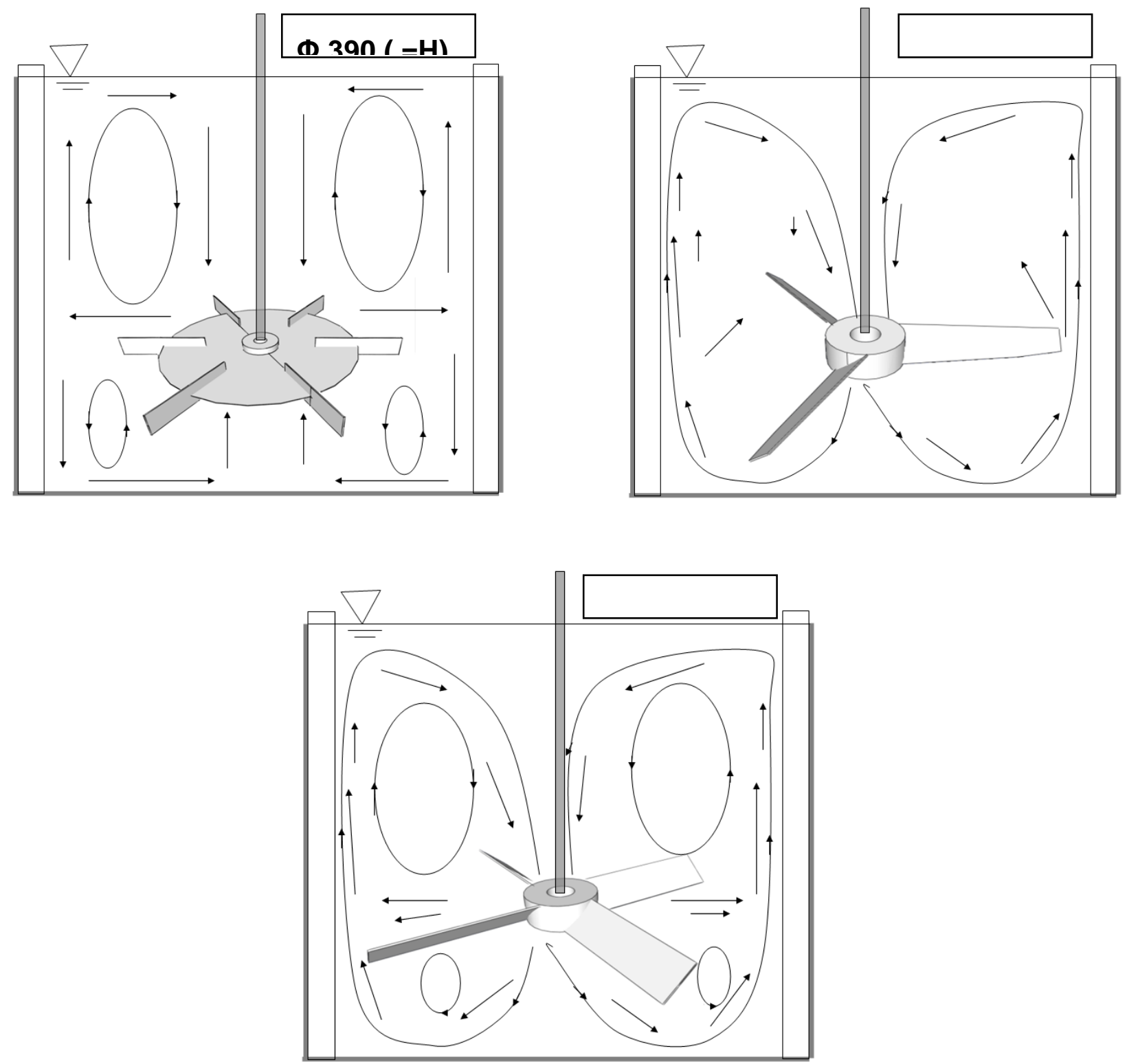

Figure 2 

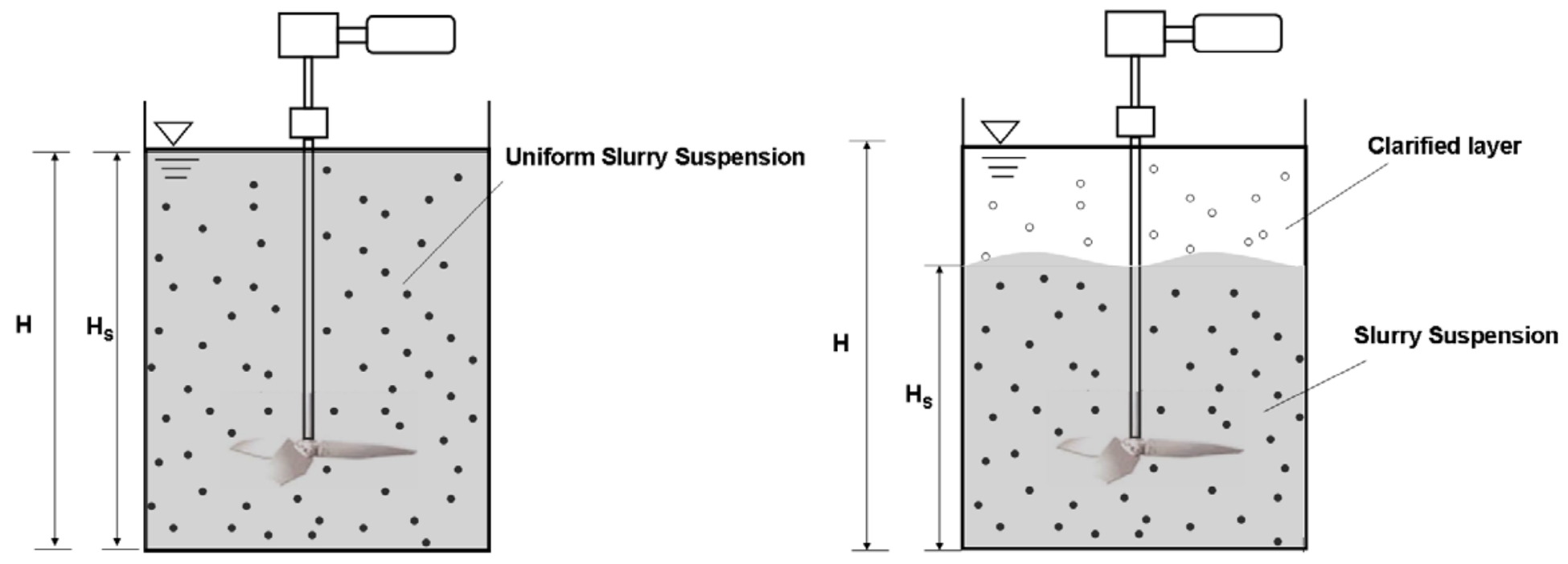

Ф
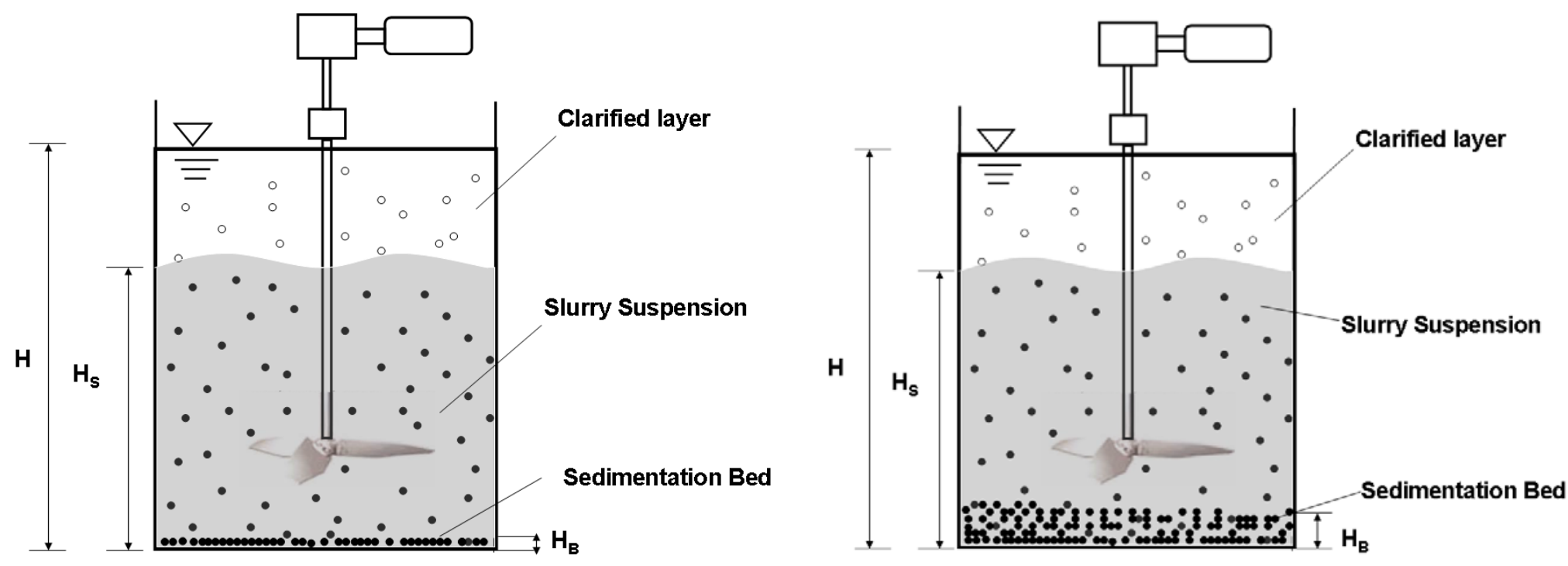

Figure 3 


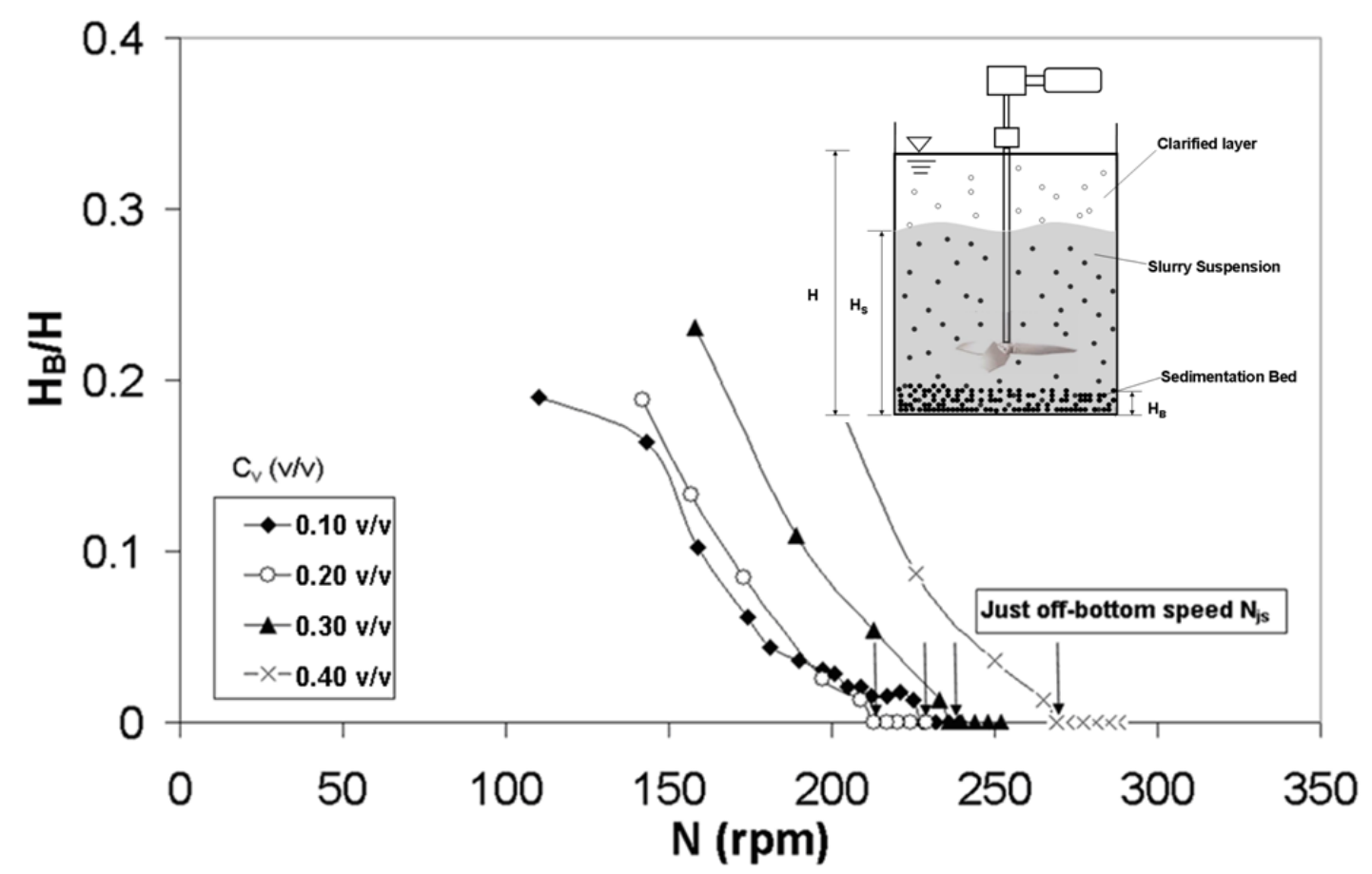

Figure 4 


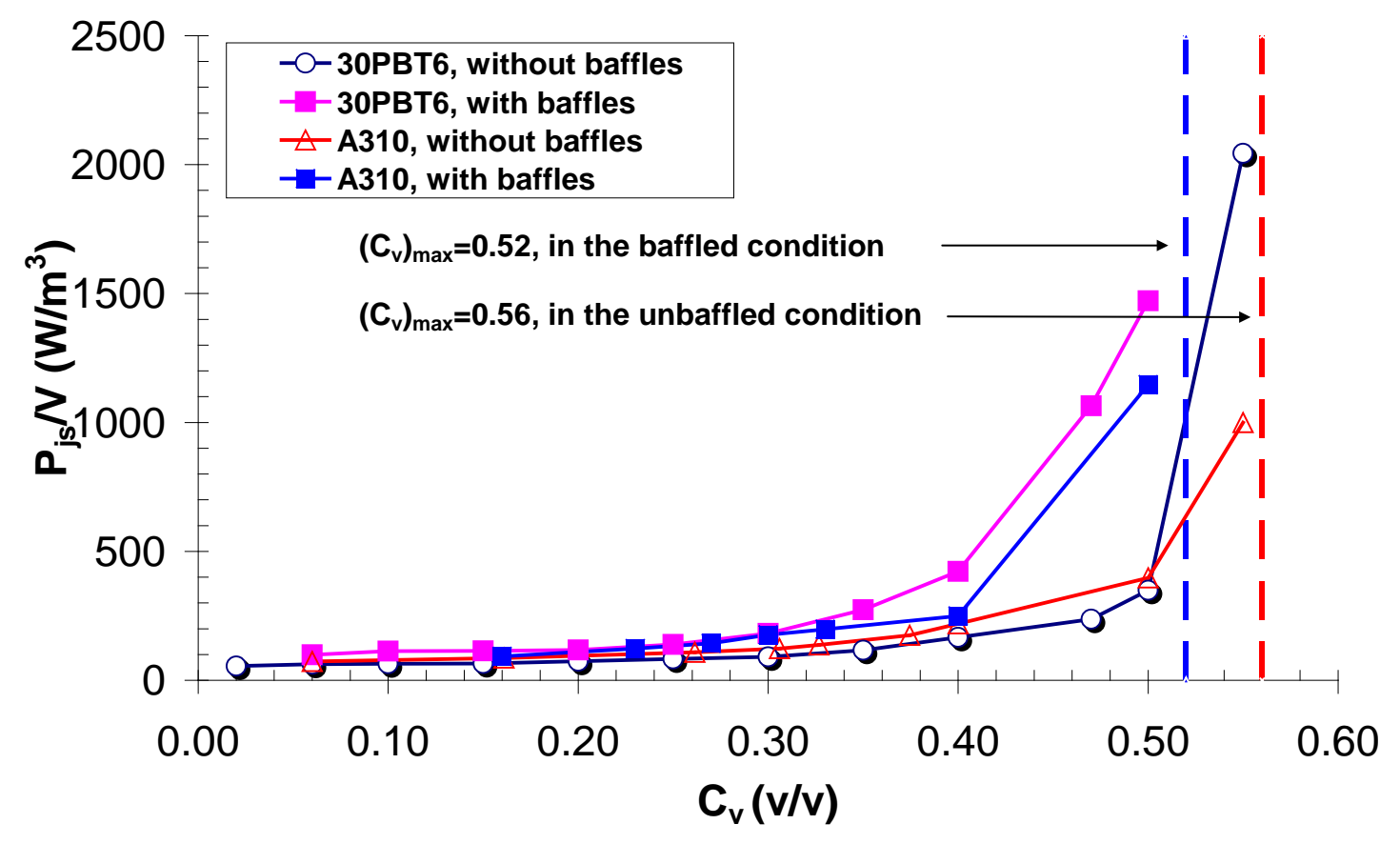

Figure 5 


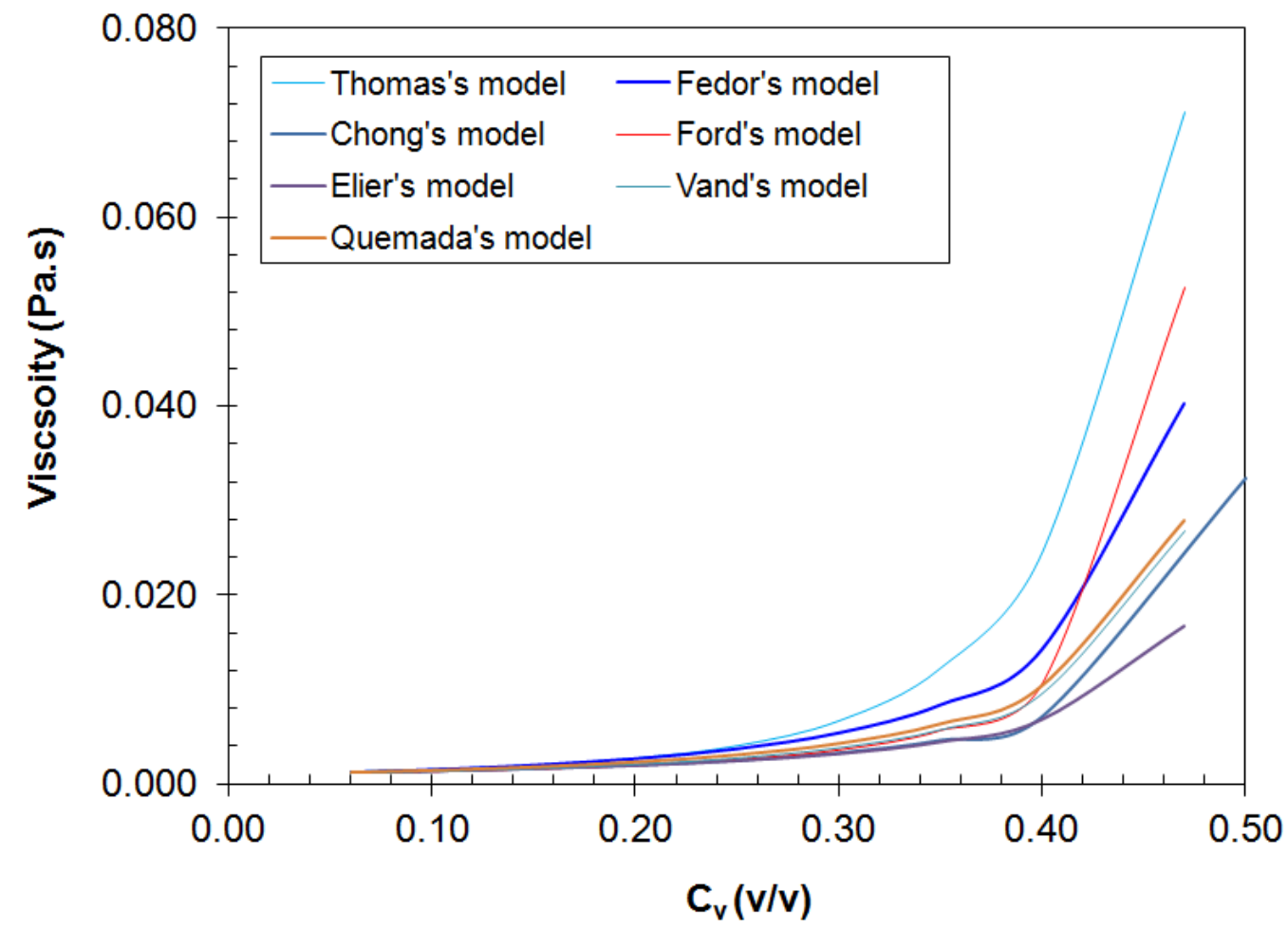

Figure 6 


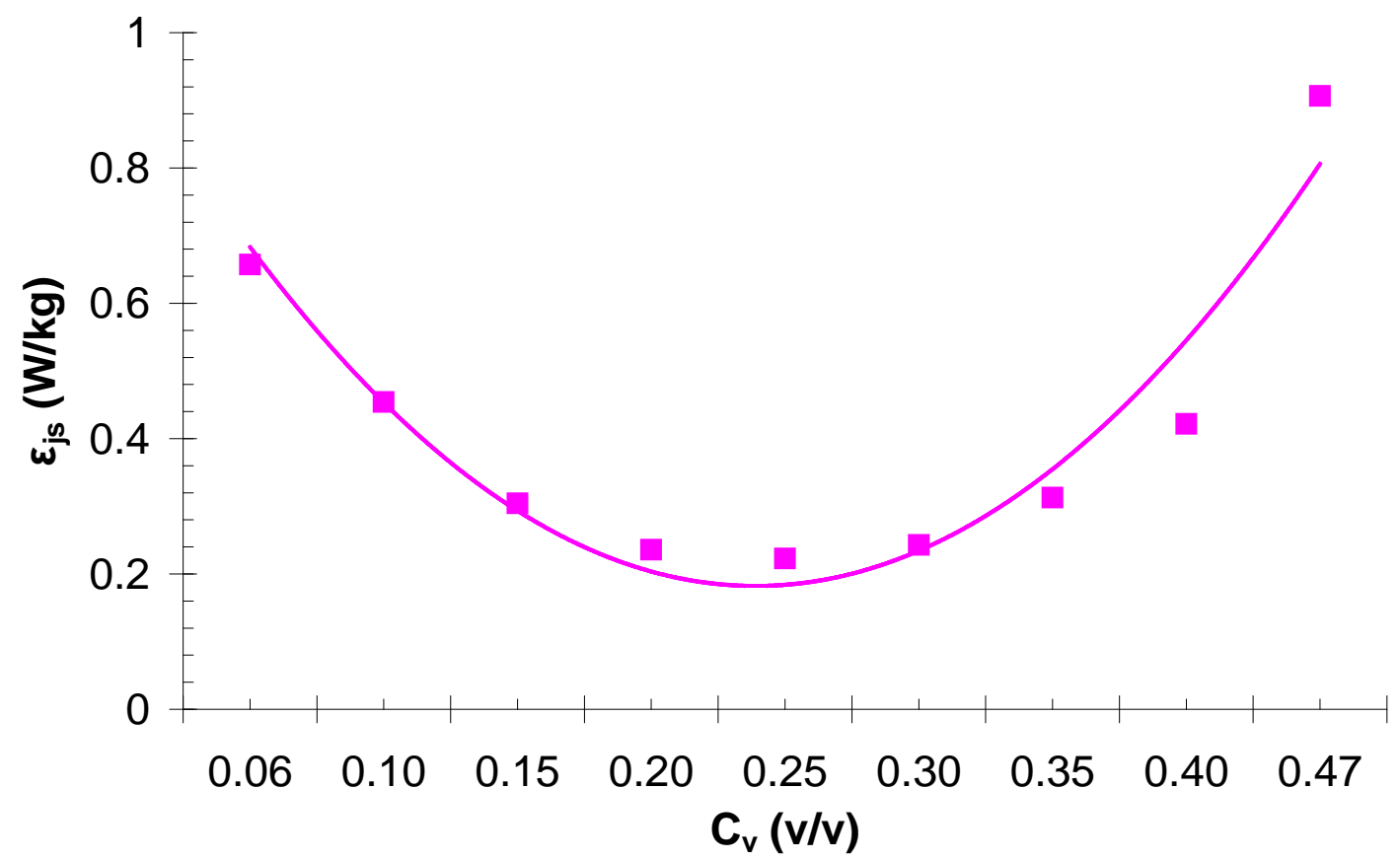

(a)

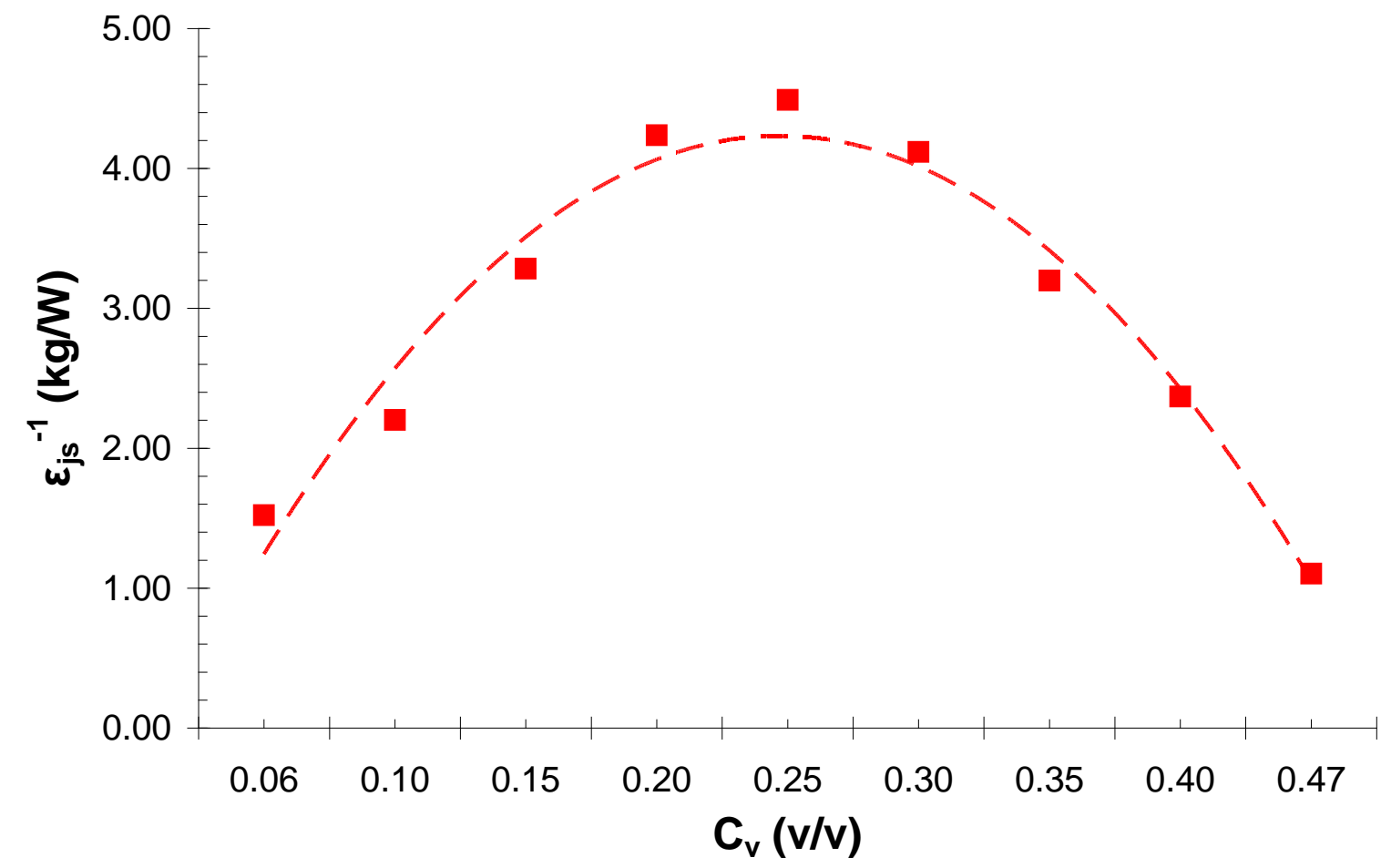

(b)

Figure 7 


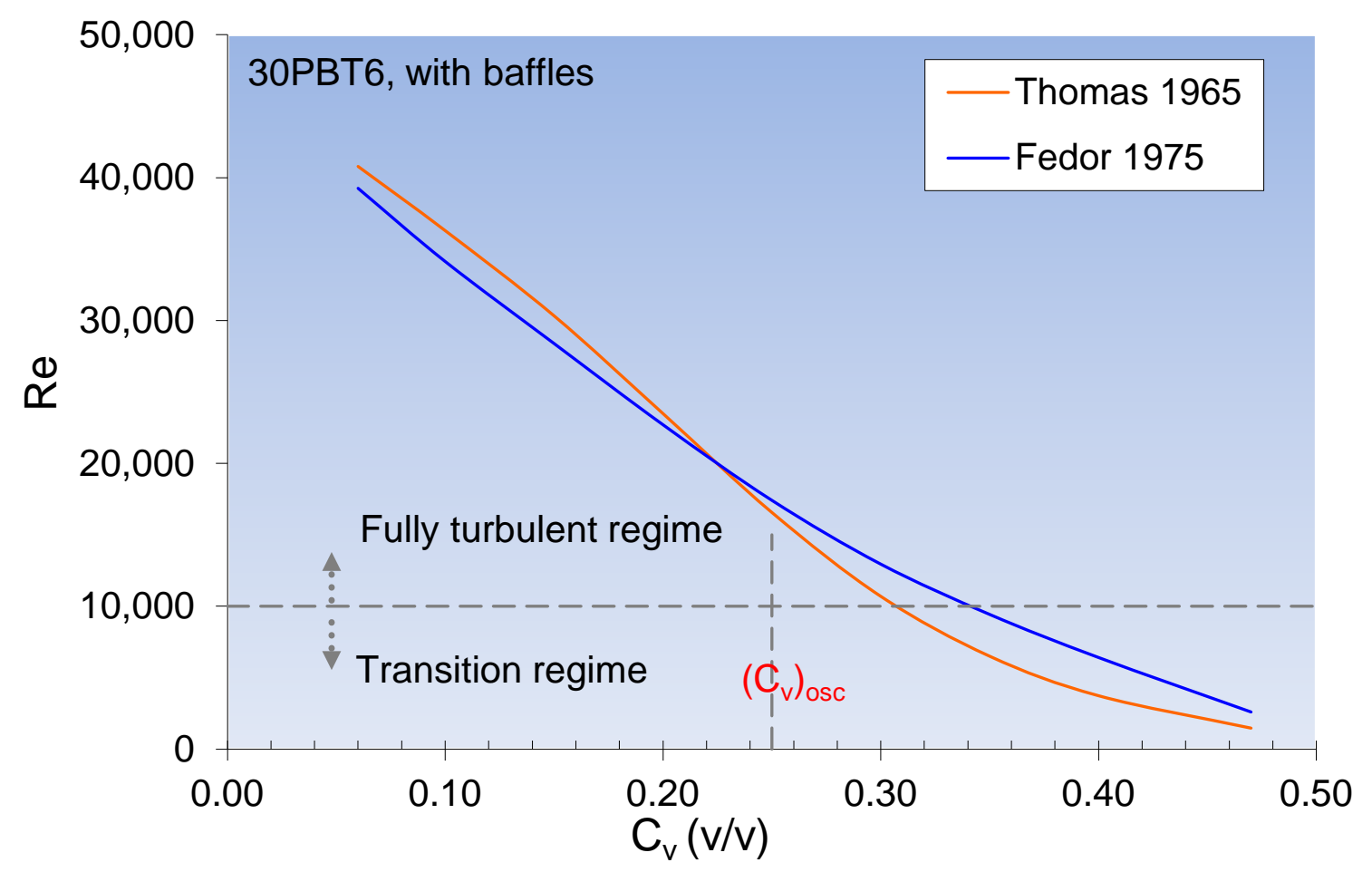

(a) with baffles

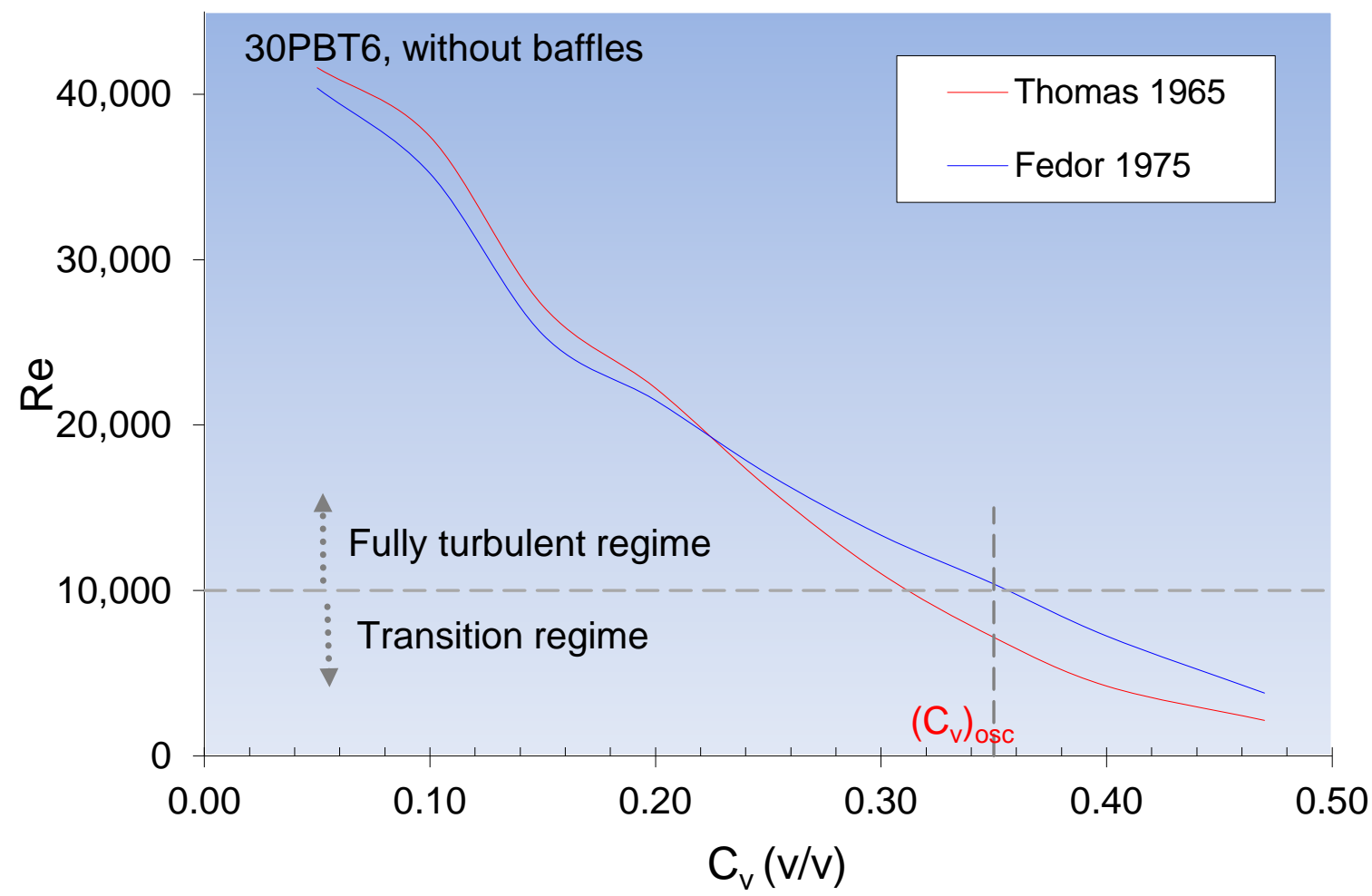

(b) Without baffles

Figure 8 


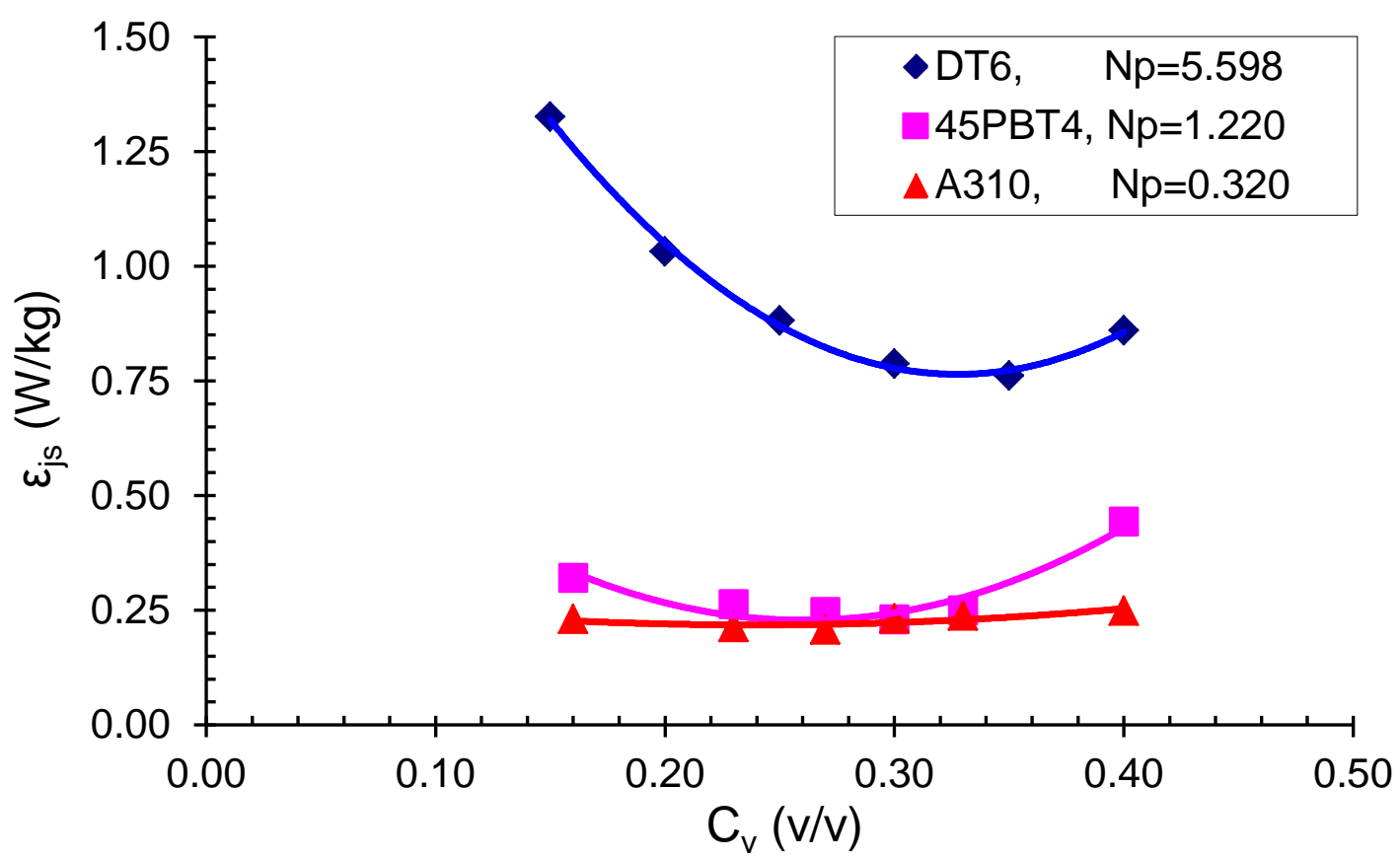

(a) With baffles

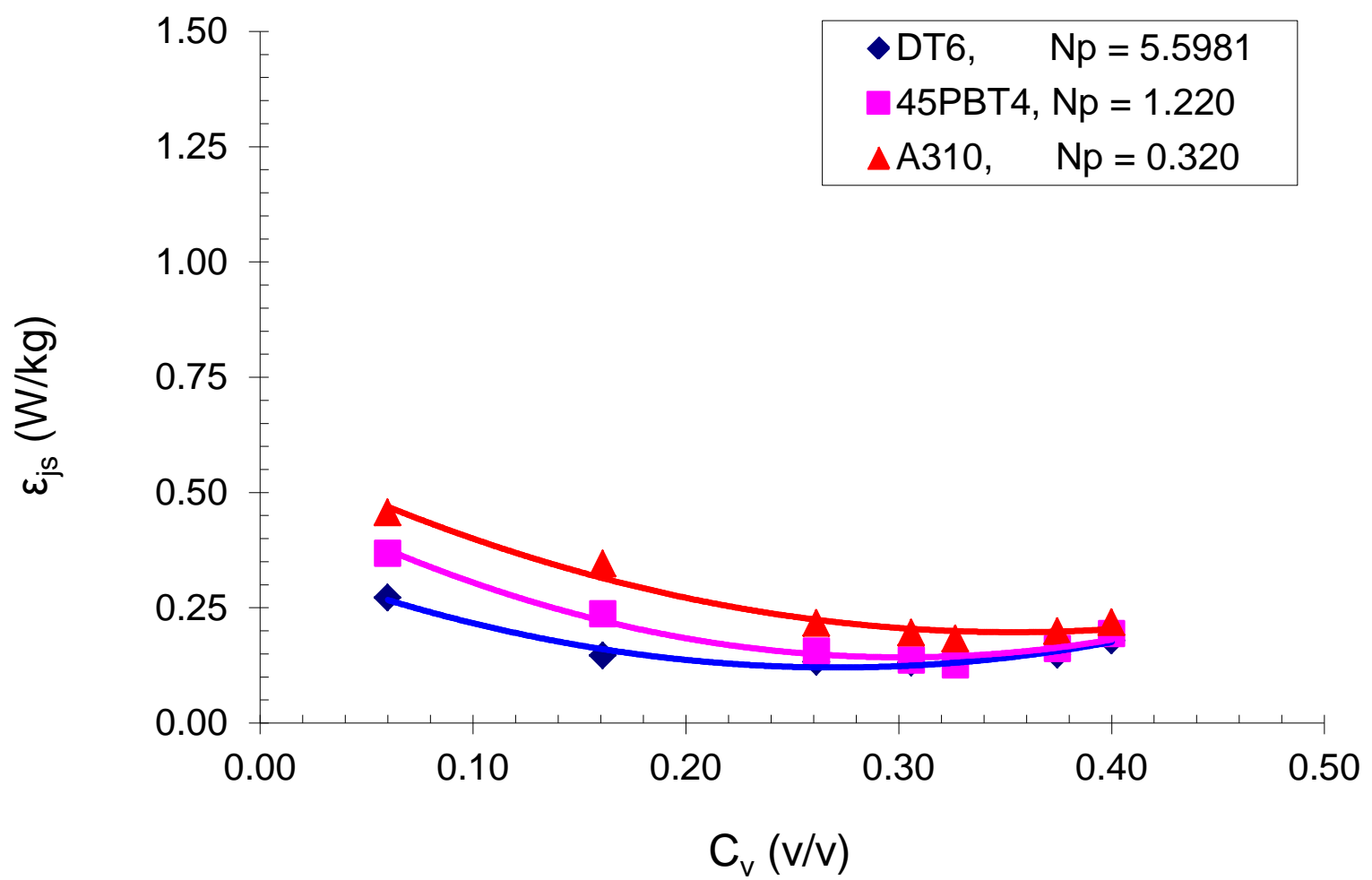

(b) Without baffles

Figure 9 

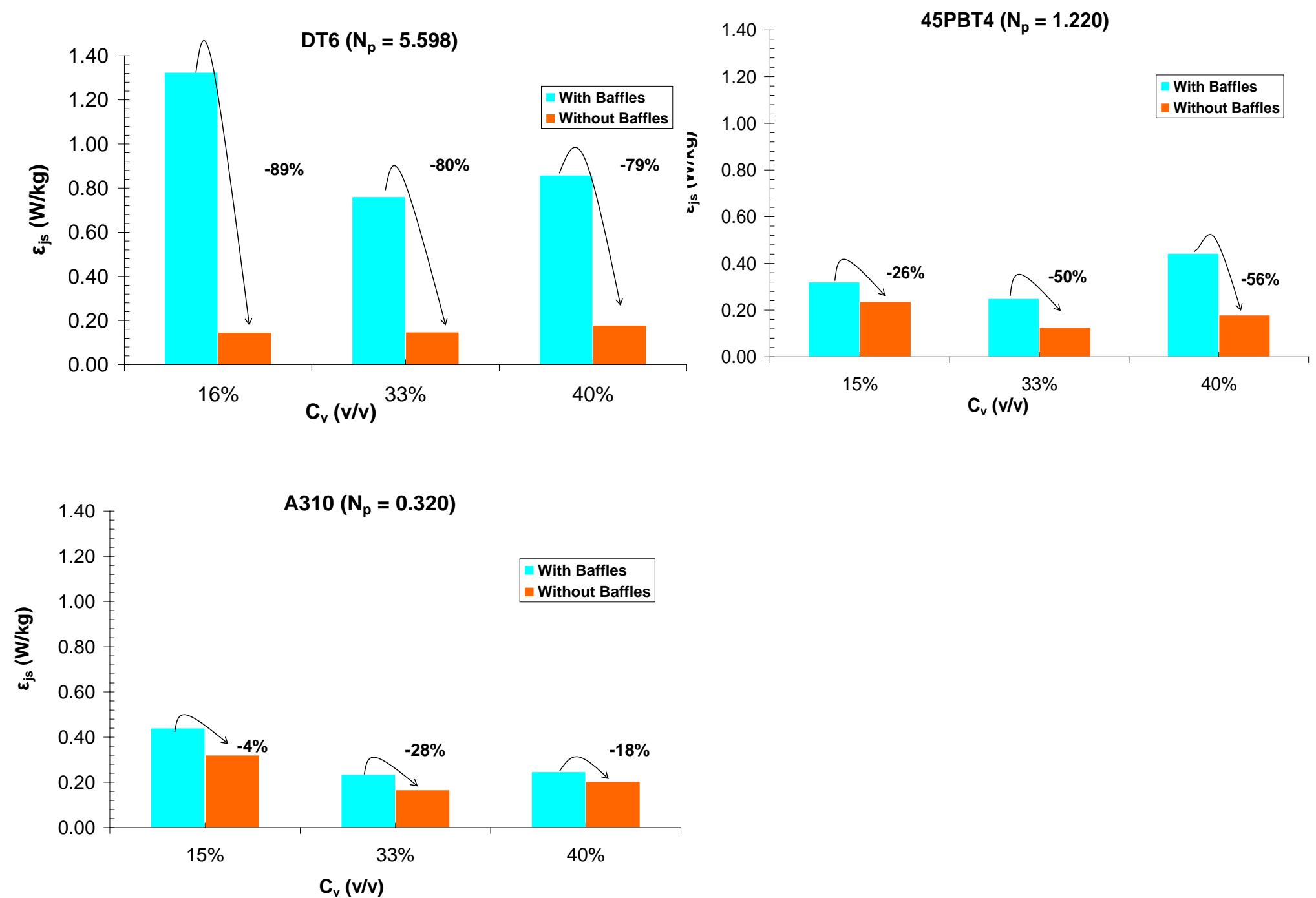

Figure 10 
(a) DT6
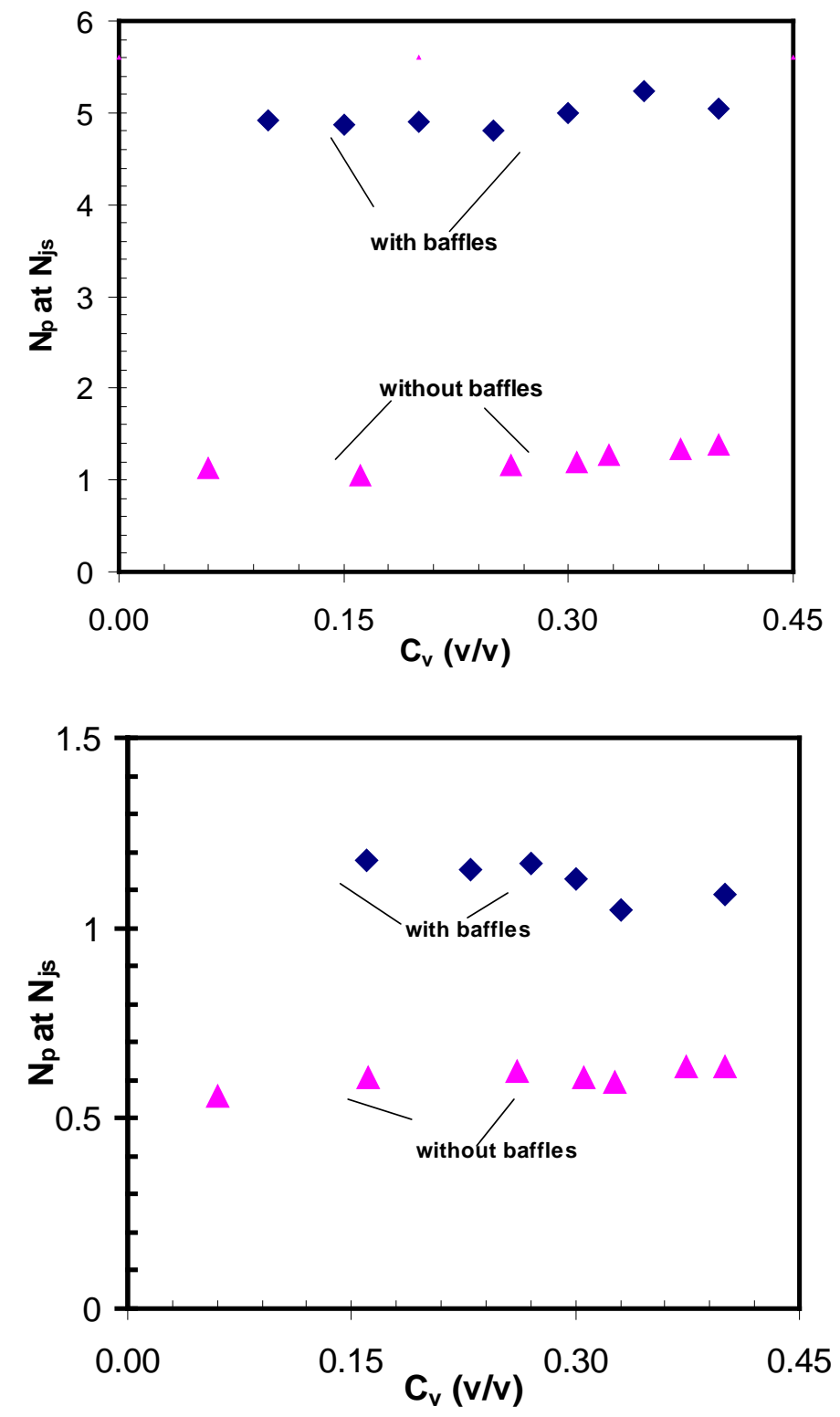

(b) 45PBT4

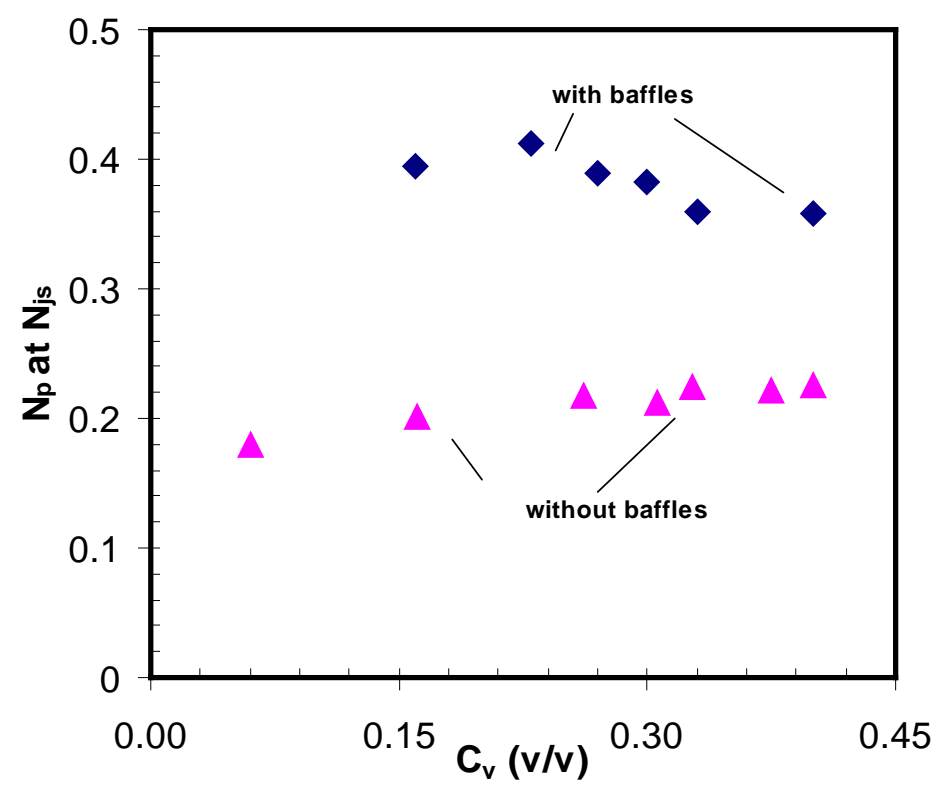

(c) A310

Figure 11 


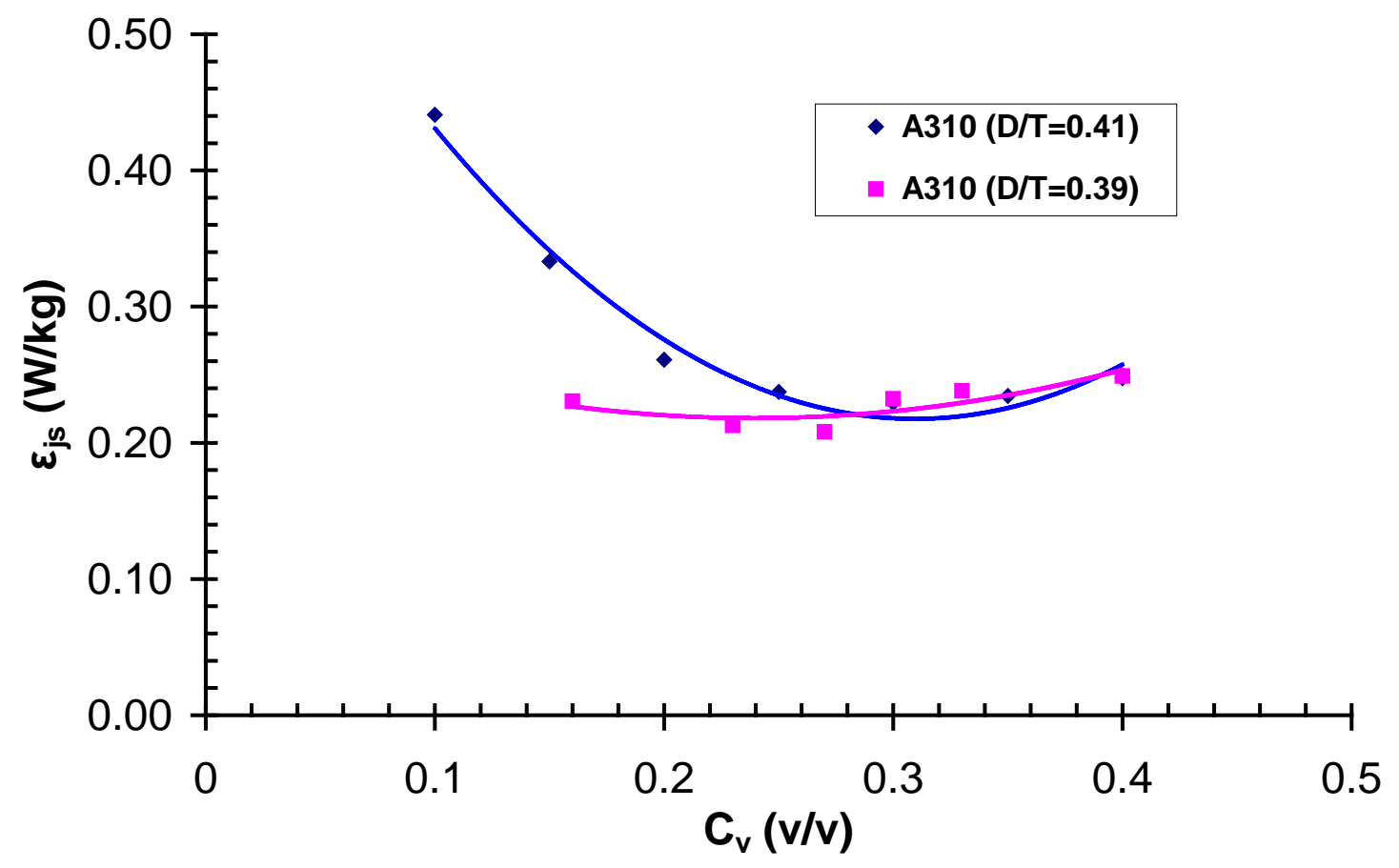

(a)

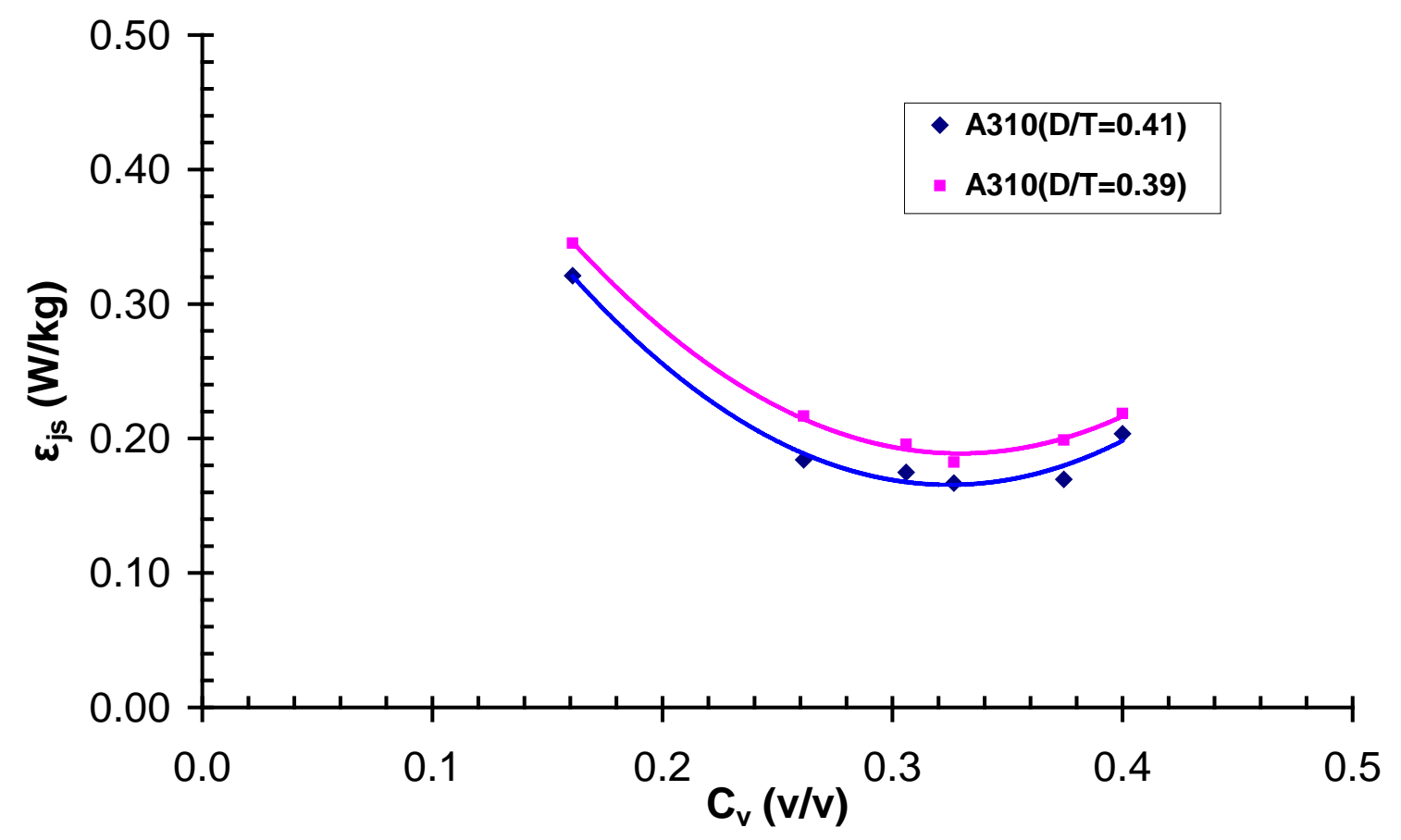

(b)

Figure 12 


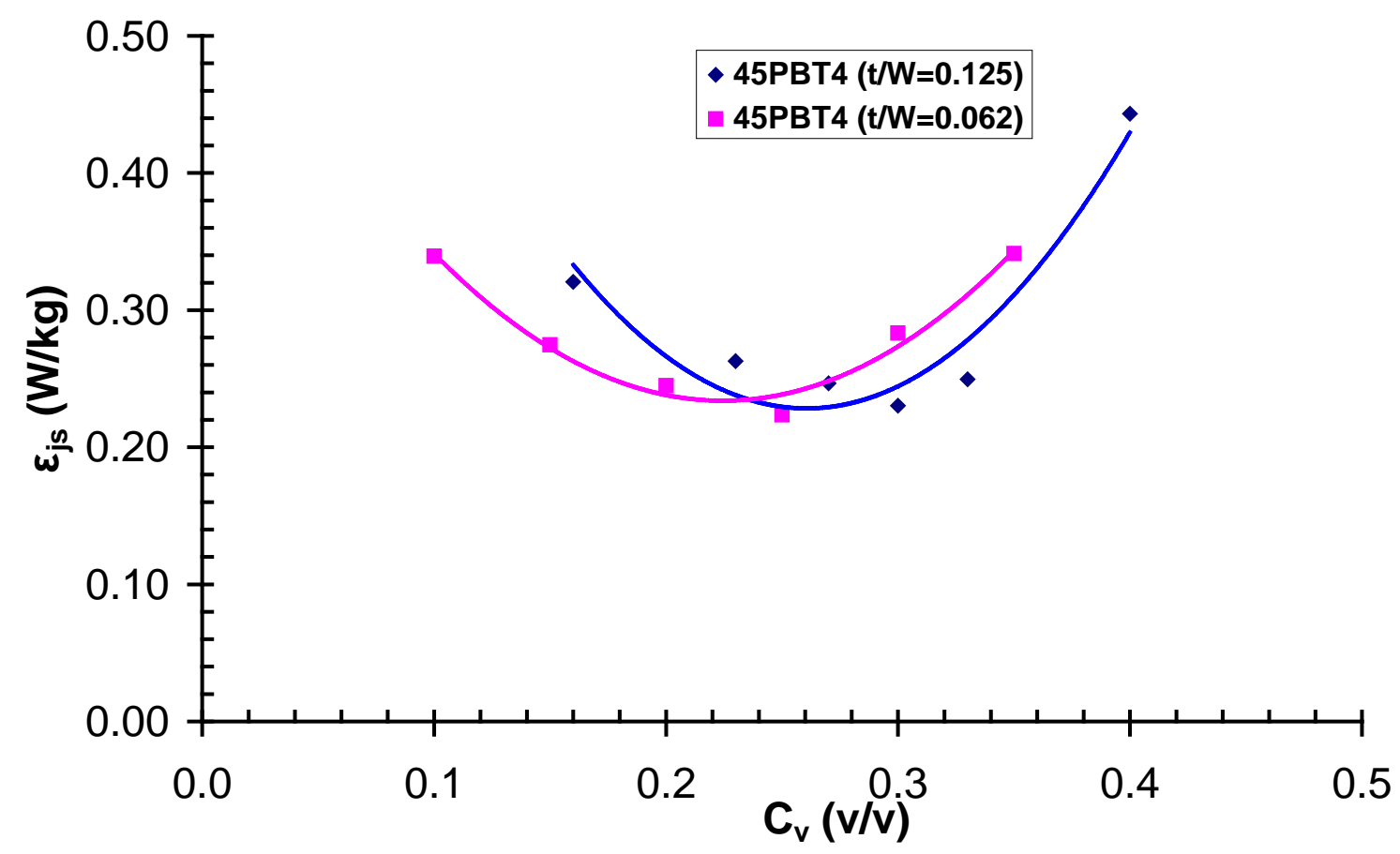

Figure 13 


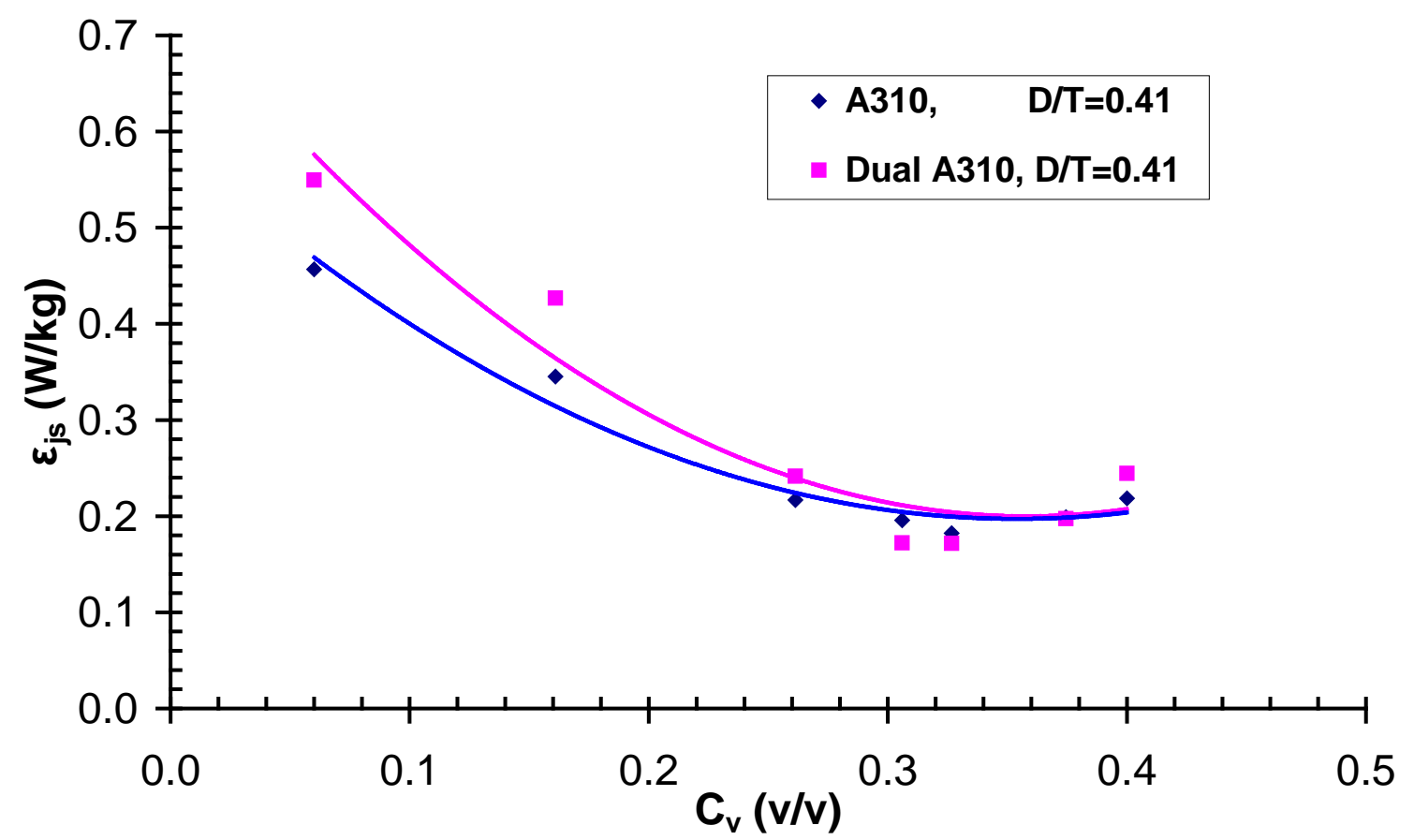

Figure 14 

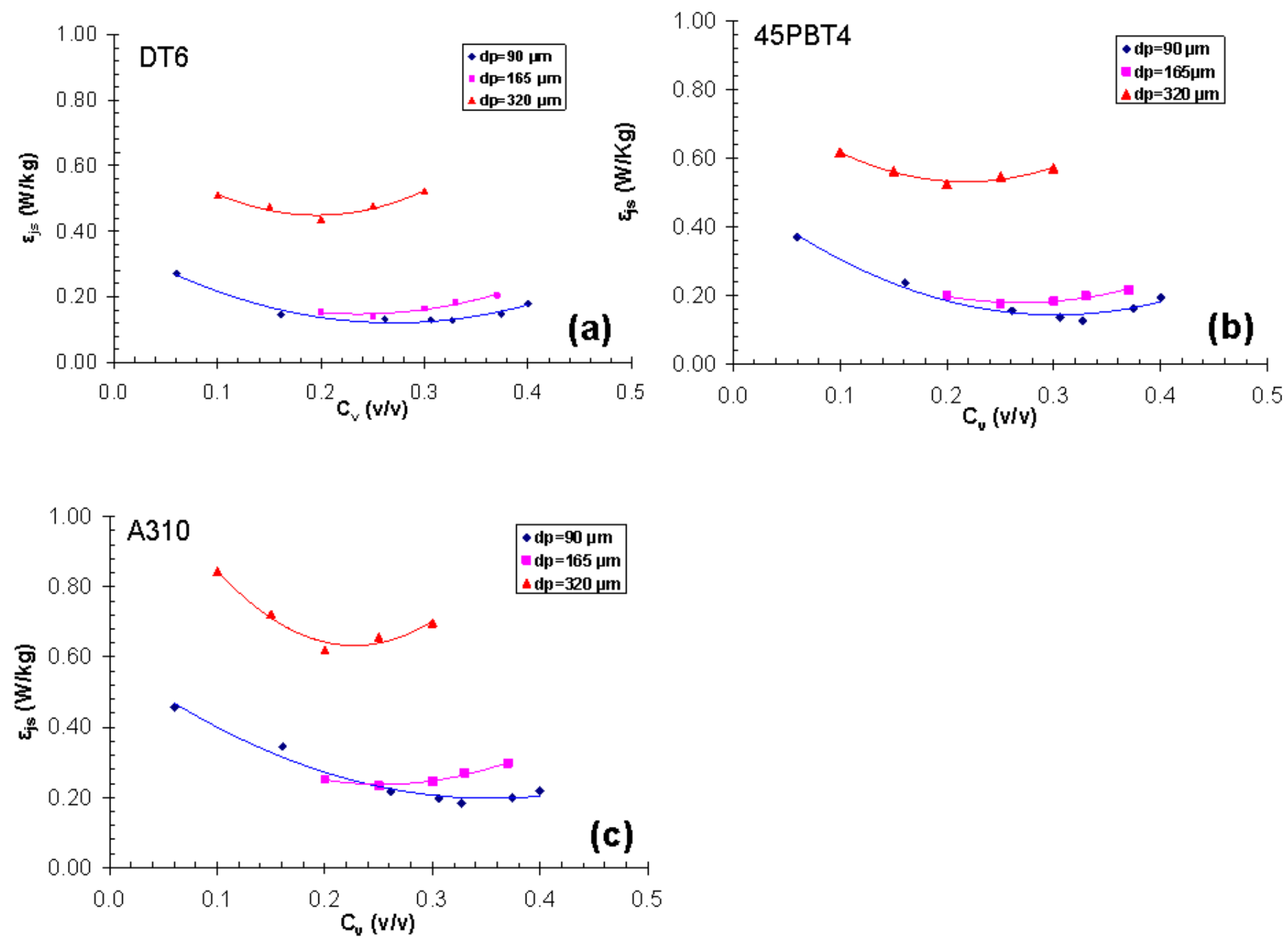

Figure 15 


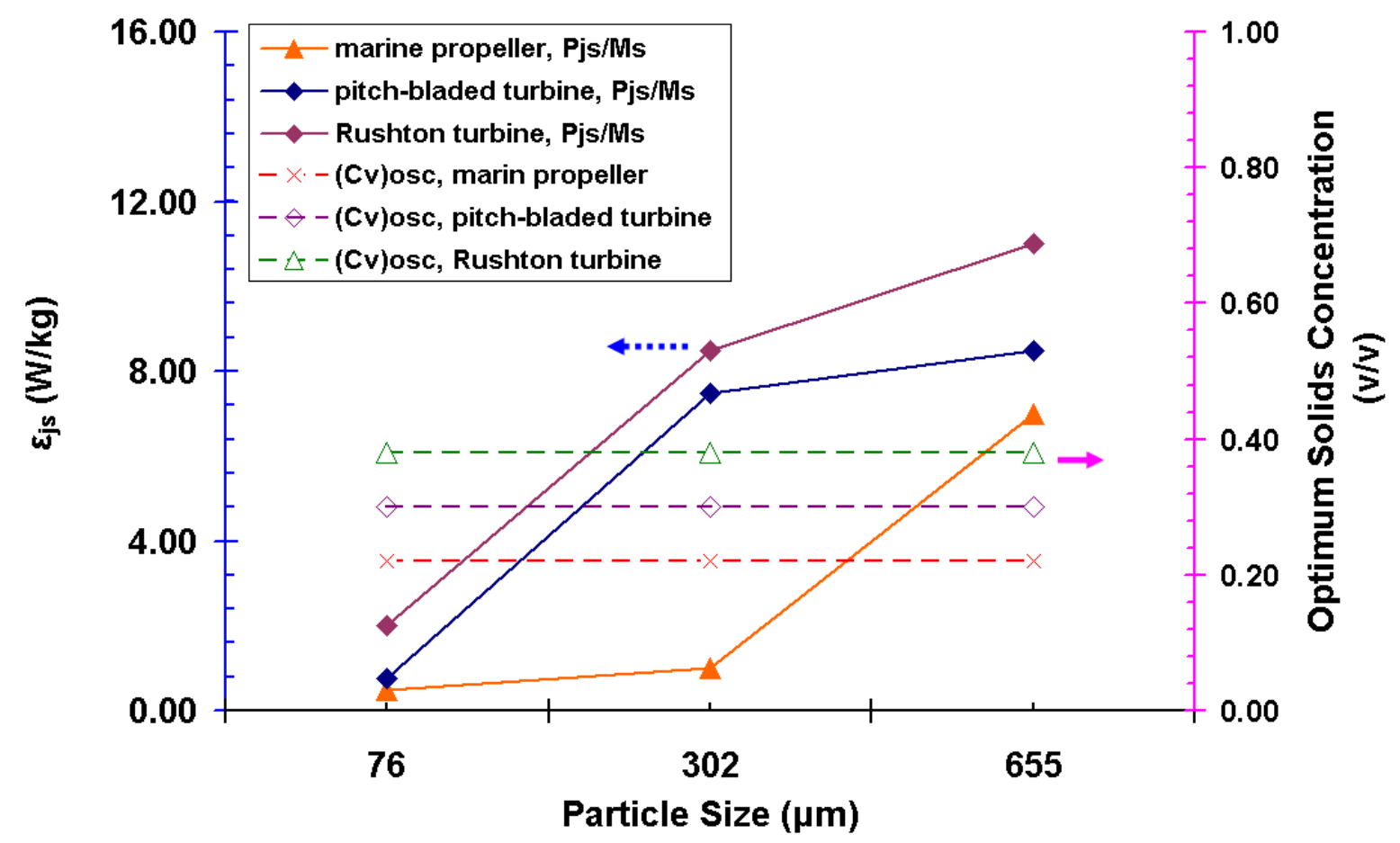

(a)

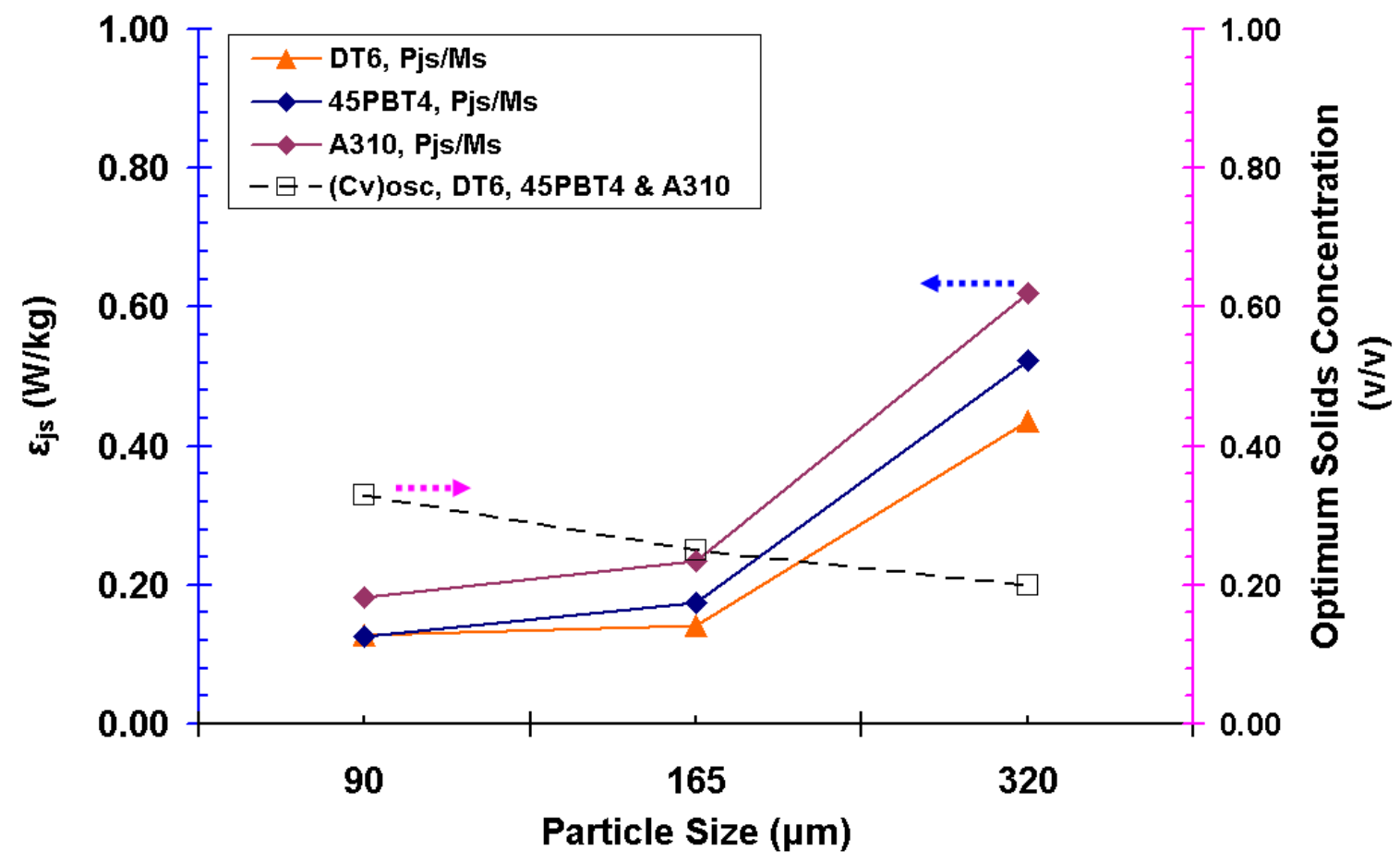

(b)

Figure 16 

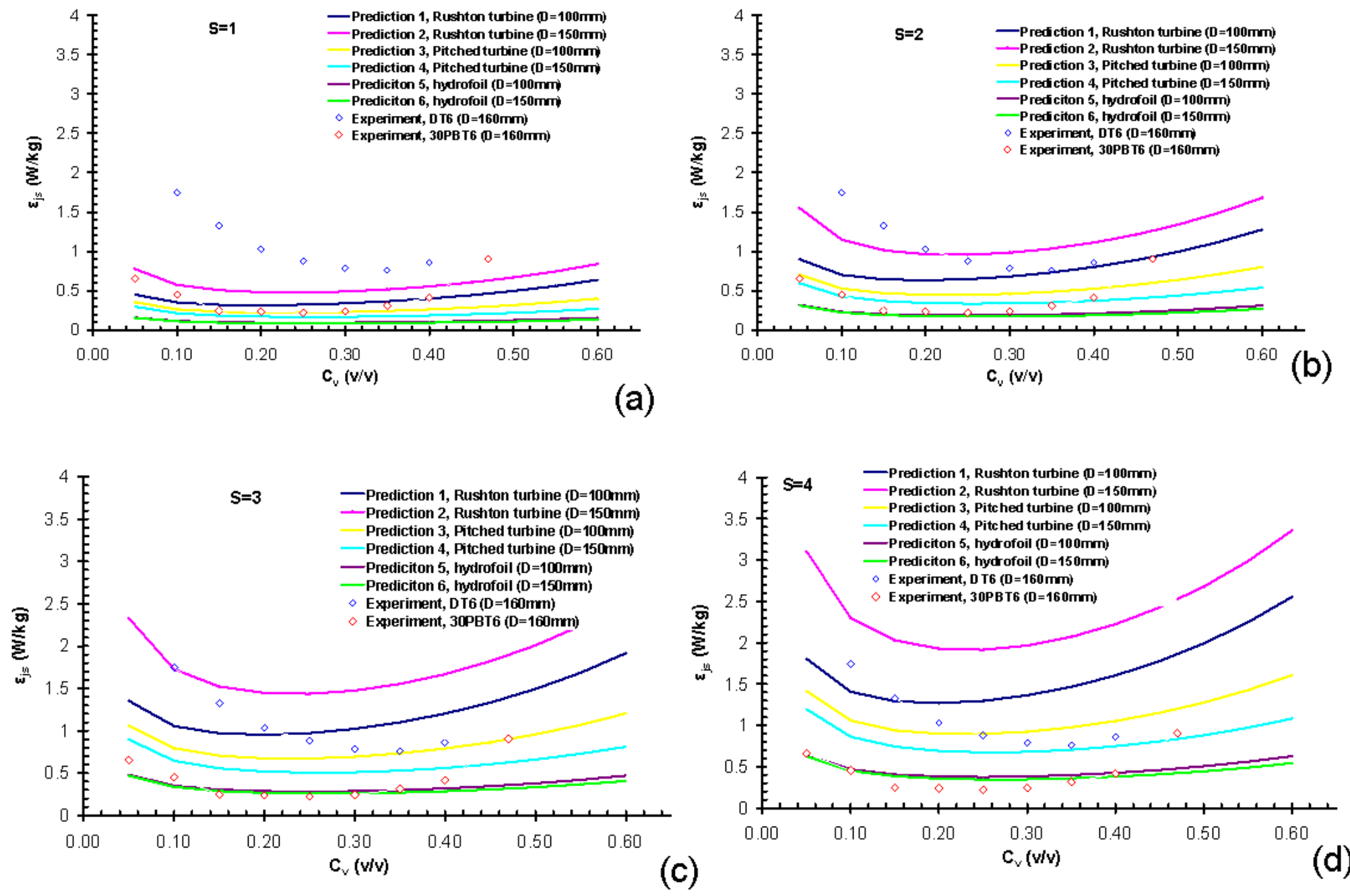

Figure 17 

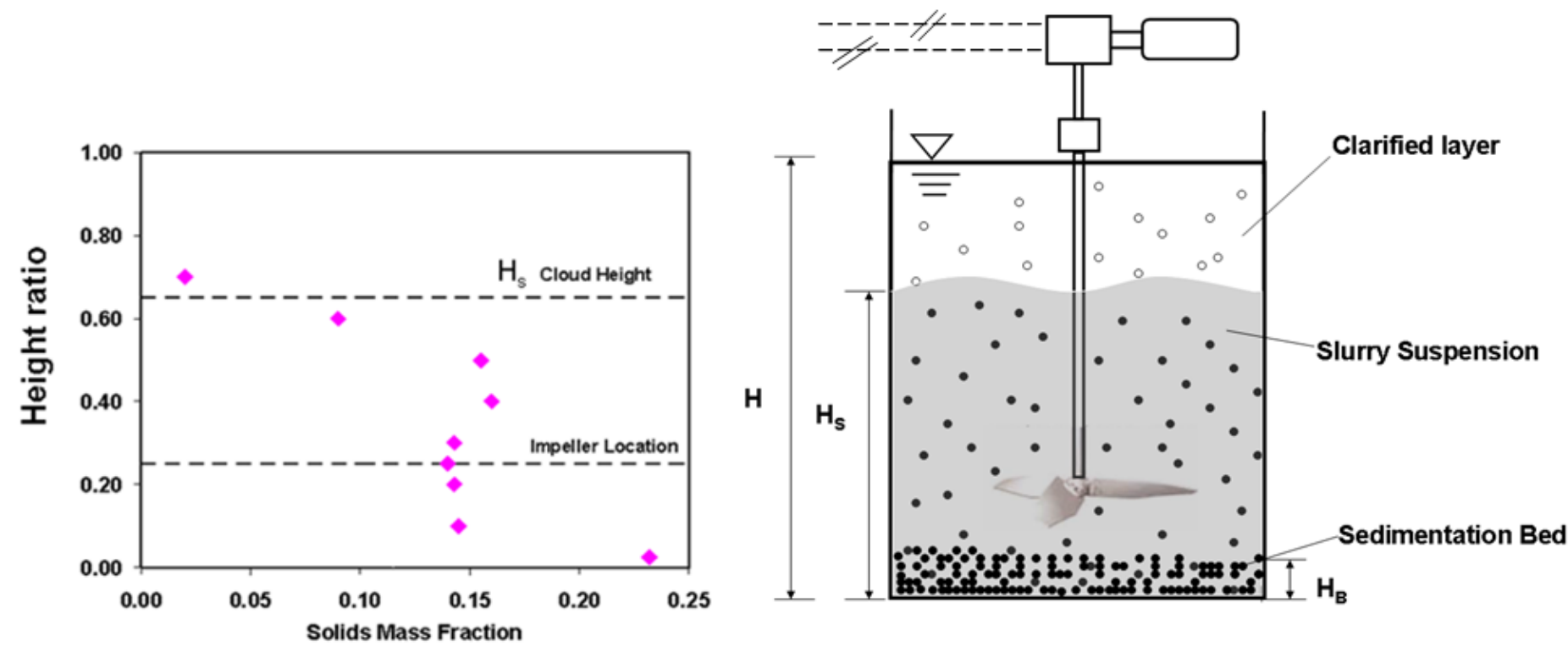

Figure 18 

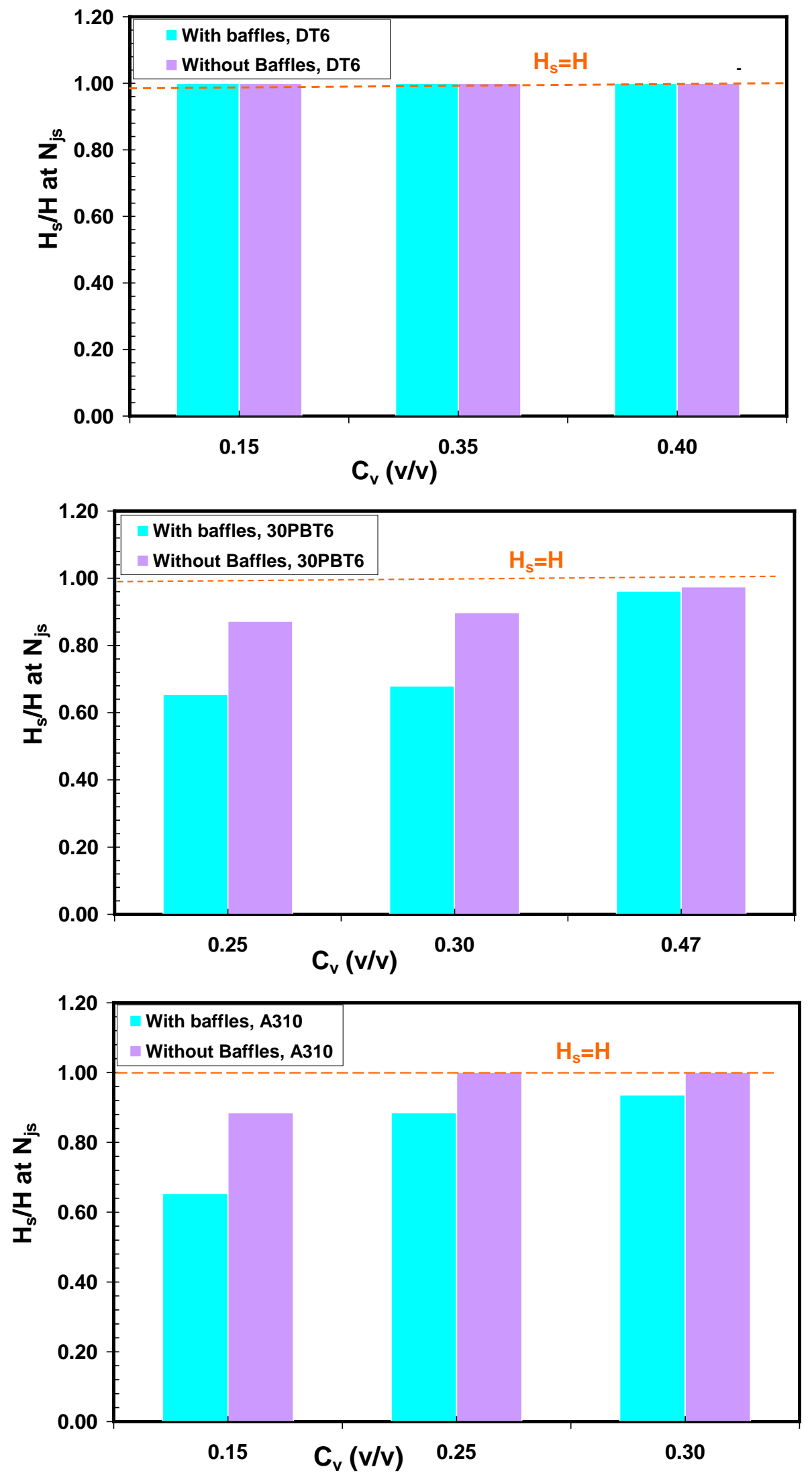


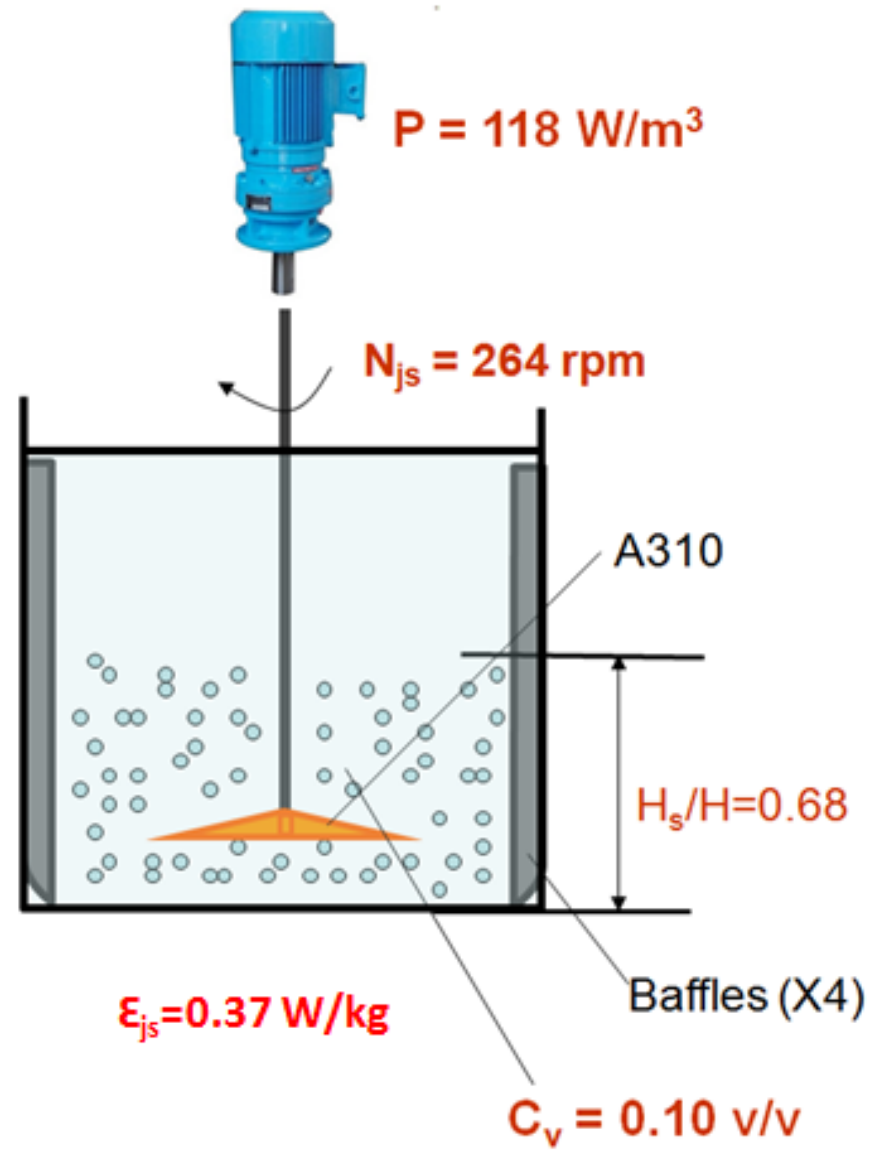

(a)

Figure 20

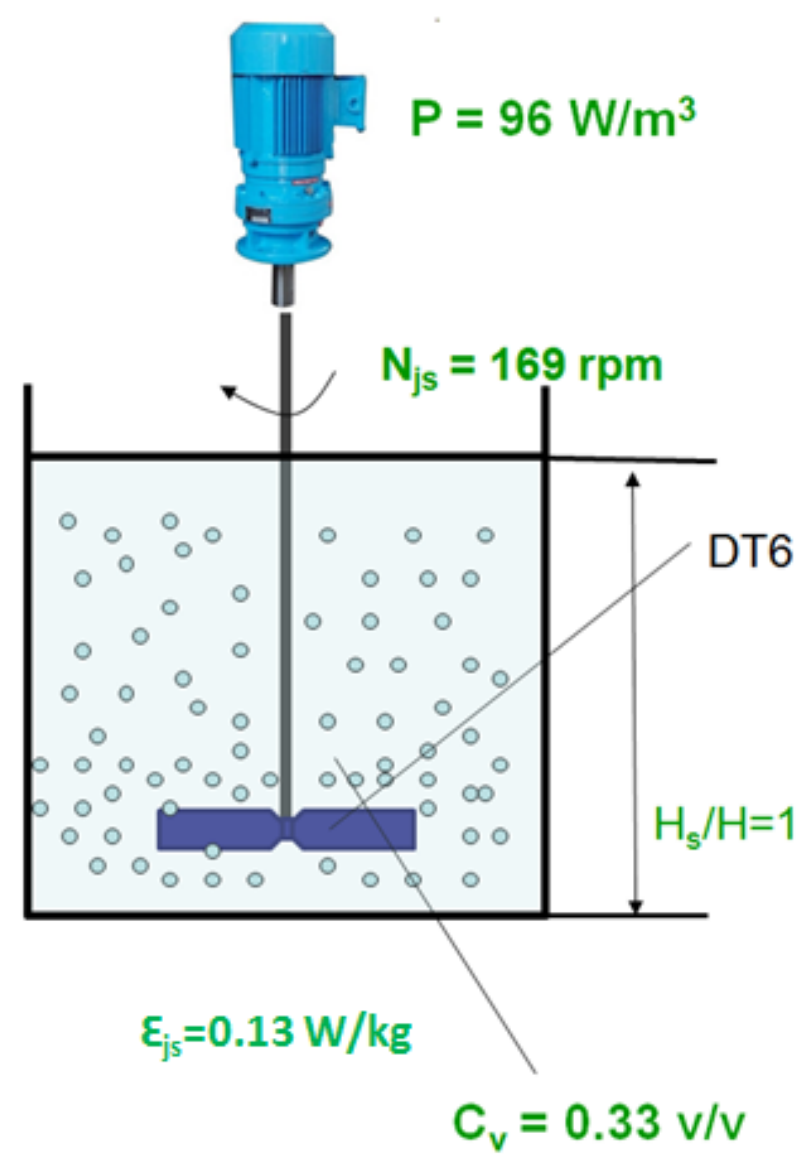

(b) 